\title{
MDCT of acute subaxial cervical spine trauma: a mechanism-based approach
}

\author{
Sameer B. Raniga • Venugopal Menon • \\ Khamis S. Al Muzahmi • Sajid Butt
}

Received: 9 September 2013 / Revised: 22 November 2013 / Accepted: 13 January 2014 / Published online: 21 February 2014

(C) The Author(s) 2014. This article is published with open access at Springerlink.com

\begin{abstract}
Injuries to the spinal column are common and road traffic accidents are the commonest cause. Subaxial cervical spine (C3-C7) trauma encompasses a wide spectrum of osseous and ligamentous injuries, in addition to being frequently associated with neurological injury. Multidetector computed tomography (MDCT) is routinely performed to evaluate acute cervical spine trauma, very often as first-line imaging. MDCT provides an insight into the injury morphology, which in turn reflects the mechanics of injury. This article will review the fundamental biomechanical forces underlying the common subaxial spine injuries and resultant injury patterns or "fingerprints" on MDCT. This systematic and focused analysis enables a more accurate and rapid interpretation of cervical spine CT examinations. Mechanical considerations are important in most clinical and surgical decisions to adequately realign the spine, to prevent neurological deterioration and to facilitate appropriate stabilisation. This review will emphasise the variables on CT that affect the surgical management, as well as imaging "pearls" in differentiating "look-alike" lesions with different surgical implications. It will also enable the radiologist in writing clinically relevant $\mathrm{CT}$ reports of cervical spine trauma.

Teaching Points

- Vertebral bodies and disc bear the axial compression forces, while the ligaments bear the distraction forces.
\end{abstract}

S. B. Raniga $(\bowtie) \cdot$ K. S. Al Muzahmi

Division of Radiology, Khoula Hospital, PO BOX 794,

Muscat 117, Oman

e-mail: sameerraniga@yahoo.com

V. Menon

Orthopedic and Spine Surgery, Khoula Hospital, PO BOX 794,

Muscat 117, Oman

S. Butt

Division of Radiology, Royal National Orthopaedic Hospital,

Stanmore, London, UK
- Compressive forces result in fracture and distractive forces result in ligamentous disruption.

- Bilateral facet dislocation is the most severe injury of the flexion-distraction spectrum.

- Biomechanics-based CT reading will help to rapidly and accurately identify the entire spectrum of injury.

- This approach also helps to differentiate look-alike injuries with different clinical implications.

Keywords Biomechanics $\cdot$ Multidetector computed tomography $\cdot$ Cervical vertebrae $\cdot$ Cervical spine injury . Spinal cord injury

\section{Introduction}

Injuries to the spinal column are frequently seen in clinical practice. The commonest cause of these injuries is road traffic accidents [1]. Falls, assault, penetrating and sports injuries form the remaining causes of spinal injury. The prevalence is likely to be significantly higher in patients with head trauma and those who are unconscious at presentation $[2,3]$. The subaxial cervical spine (C3-C7) is particularly vulnerable to traumatic injury due to its considerable mobility and its close proximity to the more rigid thoracic spine. This region accounts for about $65 \%$ of fractures and more than $75 \%$ of all dislocations in the spine, with fractures occurring most often at $\mathrm{C} 6$ and $\mathrm{C} 7$, and dislocations occurring most frequently between $\mathrm{C} 5-\mathrm{C} 6$ and $\mathrm{C} 6-\mathrm{C} 7$ vertebrae [1-3]. Injuries of the subaxial cervical spine occur along a wide spectrum of severity, from minor soft tissue "strains" to disastrous fracture dislocations with extensive spinal cord mutilation.

MDCT has gained widespread acceptance in the evaluation of spine trauma and many centres use MDCT as the initial and definite imaging modality in cervical spine trauma [4]. MDCT offers volume imaging with isotropic reconstruction, and 
provides quick and efficient imaging. In a polytrauma case, a single data acquisition can generate a spine dataset, visceral dataset and limb trauma data as indicated [5-7].

At our institution, cervical spine $\mathrm{CT}$ in trauma is performed with a 64-detector CT scanner with a $0.625-\mathrm{mm}$ detector configuration from clivus to T3. The isotropic dataset is used to generate multiplanar reformats and $3 \mathrm{D}$ reconstruction. Two-millimetre axial, coronal and sagittal reformats are generated in both soft tissue and bone algorithms. CT angiography for assessment of the vertebral artery is performed when vertebral artery injury is suspected.

Cervical spine injuries occur in a specific and predictable pattern that is generally dependent on the mechanism of injury. The pattern may be easily recognised on imaging studies, referred to as the "fingerprints" of the injury- a concept popularised by Daffner et al. [8-11]. Considering the injury mechanism and understanding the patho-anatomy are important for the surgical decision-making process. Mechanism-based image interpretation of the cervical spine will use the easily detected lesions like fracture and dislocation to predict subtle but important abnormalities, which can potentially be missed.

In this article we review the fundamental traumatic forces that cause subaxial cervical spine injuries and illustrate their associated MDCT findings. Subsequently, we apply this knowledge to the analysis of cervical spine CT images and show how an understanding of the injury mechanisms can lead to the diagnosis of subtle but important abnormalities.

\section{Structural and functional anatomy of subaxial cervical spine}

The subaxial cervical spine includes the $\mathrm{C} 3-\mathrm{C} 7$ vertebrae. A typical cervical vertebra has an anterior vertebral body and a posterior neural arch (Fig. 1). The discoligamentous complex (DLC) consists of intervertebral discs and spinal ligaments that bind adjacent vertebrae to each other and guide segmental motion and contribute to the intrinsic stability of the spine by limiting excessive motion. Anatomical components of the DLC include the anterior longitudinal ligament (ALL), intervertebral disc, posterior longitudinal ligament (PLL), facet joint capsule, ligamentum flava, interspinous and supraspinous ligaments (Fig. 2). A functional spinal unit (FSU) or spinal motion segment is the smallest anatomical unit of the spine to exhibit the biomechanical characteristics of the entire spine $[12,13]$. The spine motion segment consists of two adjacent vertebrae connected together by the DLC. Biomechanically, the spinal motion segment can be divided into anterior and posterior columns [12, 14]. The anterior column is anterior to PLL and includes the vertebral body, intervertebral disc, ALL and PLL. Posterior column is posterior to the PLL and consists of the neural arch and the posterior

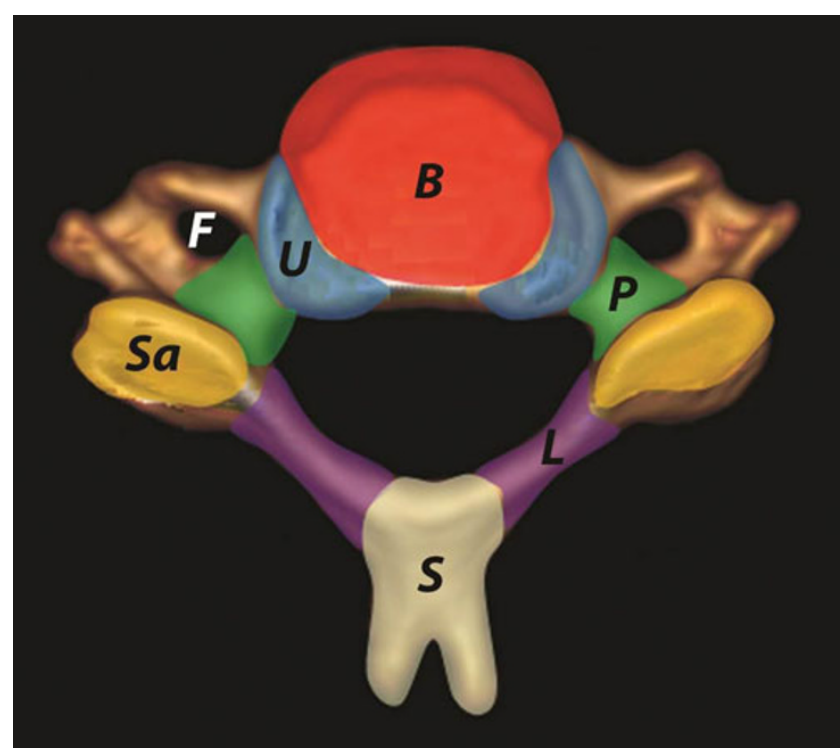

Fig. 1 Typical cervical vertebra anatomy. Vertebral body $(B)$ is anteriorly located $(r e d)$-cylindrical in shape, pedicles $(P)$ are directed posterolaterally (green), laminae $(L)$ are directed posteromedially (purple) and give rise to spinous process $(S)$ with bifid tip (light yellow). Vertebral canal is triangular. Transverse processes contain vertebral foramen $(F)$ and vertebral artery passes through it. Lateral masses are seen at the junction of pedicle and lamina - contains the articular facet at the superior ( $S a$, orange) and inferior aspect. Uncinate process $(U)$ arises from the posterolateral corner of the vertebral body's superior surface (blue)

ligamentous complex (PLC) (Fig. 2). The PLC is the primary tension band of the spinal motion segment preventing hyperflexion, torsion and anterior-posterior shear or translation $[15,16]$. The ALL is the strongest anterior ligamentous structure preventing hyperextension [17, 18]. Vertebral bodies and intervertebral discs bear the compressive loads on the spine, while the ligaments bear rotational, distractive and shear forces (Fig. 3) [14, 15].

\section{Biomechanics: basic concepts for radiologists}

Most of the severe cervical spine injuries result from direct contact from head impact. Non-contact injuries to the neck are commonly referred to as whiplash injuries and result from unrestrained neck motion during a motor vehicle collision. Within a given injury mechanism, there is a spectrum of injury, a phylogeny, which ranges from trivial to severe [19]. Mechanical subclasses are possible depending on the instant centre of rotation (fulcrum) at the moment of impact. Similar forces will result in different types of injury depending upon the fulcrum, which in turn is determined by the position of the head and neck at the time of impact.

In general, compressive forces result in burst or wedge fractures; distractive forces result in ligamentous disruption or dislocations, while rotation-shear forces result in combined 


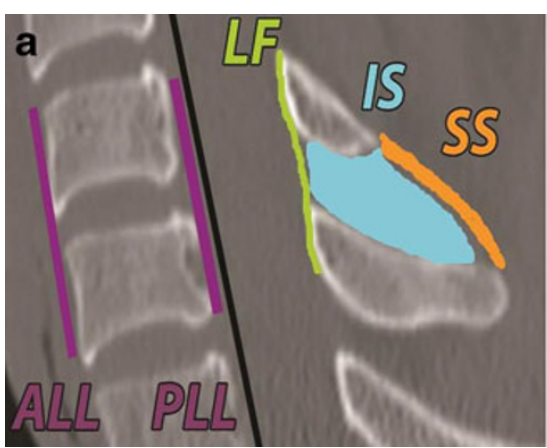

Fig. 2 Colour-coded schematic shows disco-ligamentous complex and spinal motion segment. a Spinal motion segment consists of two adjacent vertebrae connected together by the joints and ligaments. Ligamentous restrainers from anterior to posterior include: anterior longitudinal ligament $(A L L)$, intervertebral disc, posterior longitudinal ligament $(P L L)$, ligamentum flava $(L F)$, interspinous $(I S)$ and supraspinous $(S S)$

bony and ligamentous injuries producing fracture-dislocation (Fig. 4).

\section{Systematic review of MDCT of cervical spine in trauma-cchecklist"}

Missing a cervical spine injury can have potentially catastrophic neurological consequences or mechanical instability. To avoid search pattern errors on MDCT, it is helpful to have a checklist approach that will ensure that all the important structures are scrutinised for normality, and abnormality is detected if present and further characterised (Table 1).

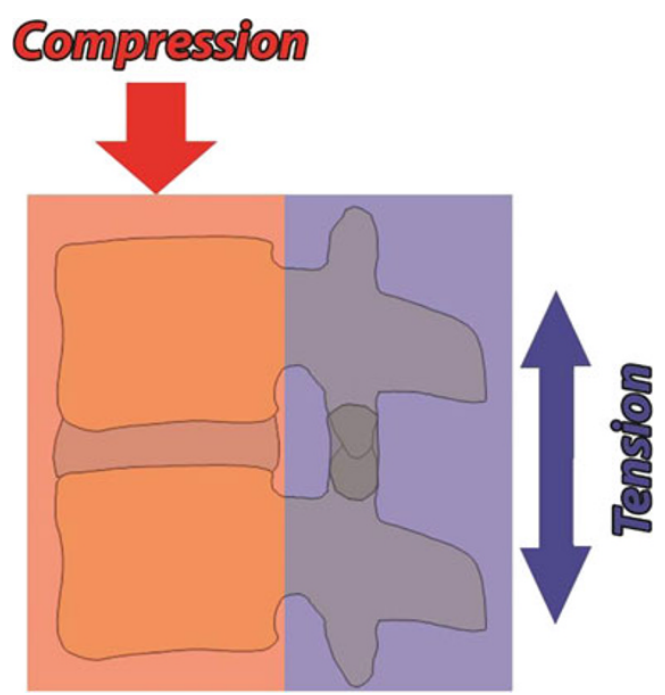

Fig. 3 The "two vertical column" concept of spine biomechanics and stability. In the two-column concept, the anterior column constitutes the ALL, vertebral body, intervertebral disc and PLL. The posterior column constitutes bony neural arch and posterior ligamentous complex (PLC). Load bearing anterior column resists compression forces. The posterior ligamentous complex including facet joints forms the principle tension band and resists distraction forces

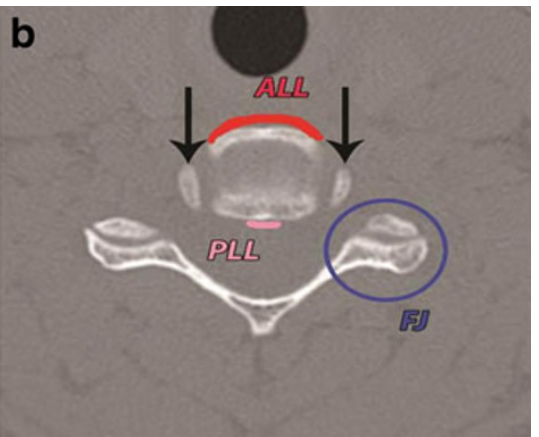

ligaments. Intervertebral disc, facet and uncovertebral joints stabilise the motion segment. b Axial CT image shows the stabilising ligaments, ALL and PLL, the facet and the uncovertebral joints. Uncinate processes (black arrows) are in symmetrical, concentric relationship at the posterolateral aspect of the cranial vertebra. The facet joint on axial image resembles a "hamburger bun" with the flat surface articulating

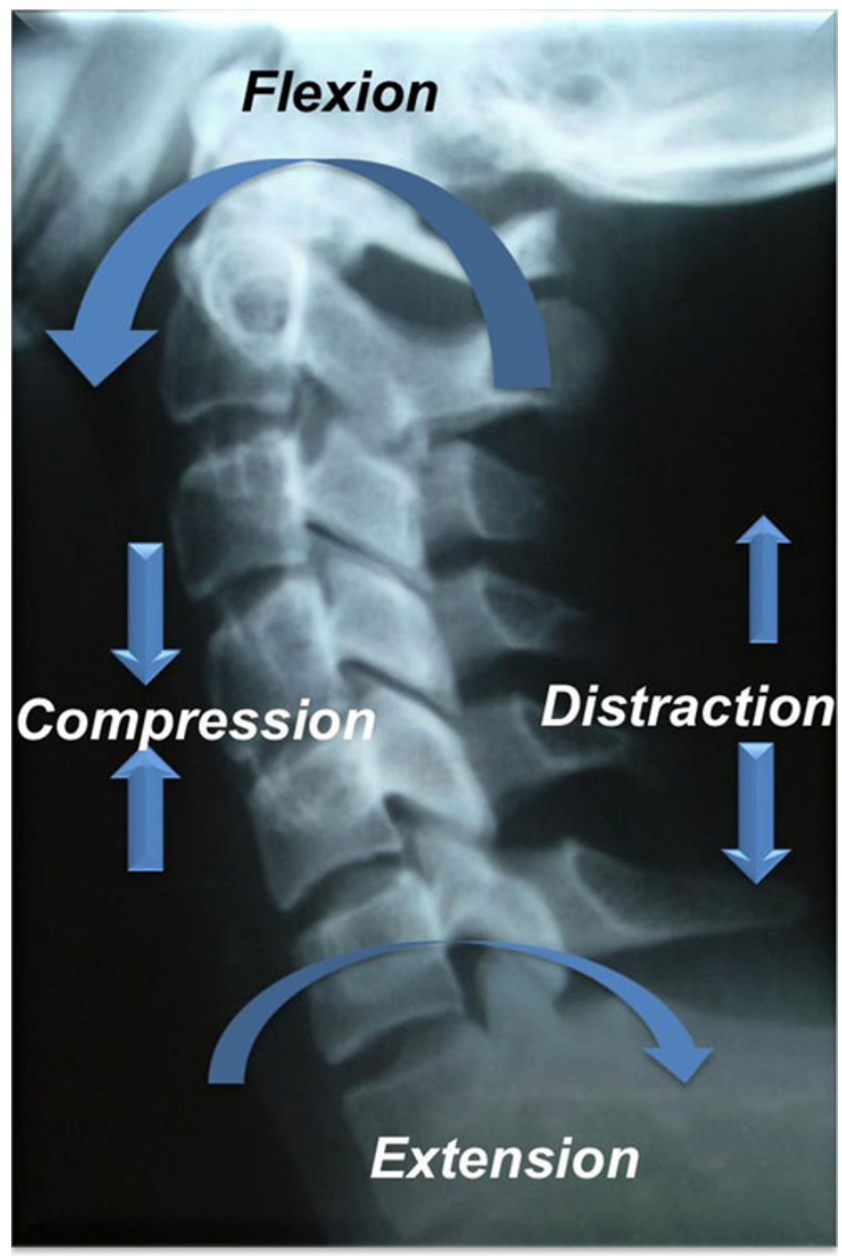

Fig. 4 Schematic shows major injury vectors and forces with their impacts on the vertebral column. Flexion injury results from supraphysiological forward bending and extension injury results from backward banding. Compression forces approximate the bones, while distraction dissociates the bones. Shear forces are applied at a right angle to the long axis of spine and produces significant bony and ligamentous disruption 
Table 1 Cervical spine trauma CT interpretation: checklist

\begin{tabular}{|c|c|c|}
\hline & Anterior column & Posterior column \\
\hline \multirow[t]{4}{*}{ Bone } & Vertebral body: & Neural arch: \\
\hline & $\begin{array}{l}\text { Normal—preserved height without wedging, smooth } \\
\text { cortices without step }\end{array}$ & $\begin{array}{l}\text { Normal—intact without fracture } \\
\text { Abnormal—fracture }\end{array}$ \\
\hline & Abnormal—fracture & Further description: comminution, Orientation of fracture line- - vertical vs \\
\hline & $\begin{array}{l}\text { Further description - comminution, Involvement of } \\
\text { posterior cortex of vertebral body, retropulsion of } \\
\text { fragments }\end{array}$ & $\begin{array}{l}\text { horizontal; unilateral vs bilateral; symmetrical vs asymmetrical; isolated } \\
\text { posterior elements or associated with anterior column fractures }\end{array}$ \\
\hline \multirow[t]{2}{*}{ Joints } & Intervertebral disc: & Facet joint: \\
\hline & $\begin{array}{l}\text { Normal—symmetrical disc space without focal widening } \\
\text { or narrowing } \\
\text { Abnormal—focal anterior or posterior widening or } \\
\text { asymmetry in coronal plane }\end{array}$ & $\begin{array}{l}\text { Normal — congruent, parallel and symmetrical } \\
\text { Abnormal - diastasis, subluxation, dislocation; focal anterior vs posterior } \\
\text { widening } \\
\text { Further description — unilateral vs bilateral Associated articular process } \\
\text { fracture }\end{array}$ \\
\hline \multirow[t]{3}{*}{ Ligaments } & ALL/PLL: & PLC: \\
\hline & $\begin{array}{l}\text { Normal integrity inferred from alignment of anterior } \\
\text { posterior vertebral lines }\end{array}$ & $\begin{array}{l}\text { Normal- Integrity inferred from the normal alignment, interspinous distance } \\
\text { and facet joint morphology }\end{array}$ \\
\hline & $\begin{array}{l}\text { Abnormal—anterior vs posterior translation. Triangular } \\
\text { avulsion at the corners of vertebral end plates }\end{array}$ & $\begin{array}{l}\text { Abnormal-Anterolisthesis, focal kyphosis, interspinous widening and facet } \\
\text { joint abnormality as mention in the previous column }\end{array}$ \\
\hline Curvature & $\begin{array}{l}\text { Normal—smooth lordosis } \\
\text { Abnormal—focal kyphosis }\end{array}$ & - \\
\hline Alignment & Anterior/posterior vertebral body lines in sagittal plane & $\begin{array}{l}\text { Spinolaminar and interspinous lines on sagittal plane } \\
\text { Interspinous and articular pillar lines in coronal plane }\end{array}$ \\
\hline Measurement & - & $\begin{array}{l}\text { Interpedicular distance. Interspinous and interlaminar distance } \\
\text { Abnormal: difference of more than } 2 \mathrm{~mm}\end{array}$ \\
\hline
\end{tabular}

The interpreting physician must be aware of the appropriate CT imaging plane for the optimal visualisation of different components of the checklist and further characterisation of abnormality (Table 2). In the sagittal plane, bony alignment on CT is evaluated by drawing: the anterior vertebral lineconnecting the anterior vertebral cortices; the posterior vertebral line-connecting the posterior vertebral cortices; the spinolaminar line - a smooth curve from opisthion to $\mathrm{C} 7$ formed by junction of laminae with spinous processes; the interspinous line - connecting the tip of the spinous processes of C3-C7. All of these lines should be in a smooth curve without focal discontinuity or angulation (Fig. 5). On the sagittal plane, the posterior vertebral line is the most reliable and accurate indicator of antero-posterior alignment.

Facet joints are best evaluated in the sagittal plane on parasagittal images (Fig. 6). On axial CT images, the

Table 2 CT checklist and optimal plane of visualisation

\begin{tabular}{|c|c|c|c|}
\hline Fingerprint & Sagittal & Axial & Coronal \\
\hline Alignment & $\begin{array}{l}\text { Anterior and posterior translation } \\
\text { Anterior and posterior vertebral line, } \\
\text { spinolaminar line, interspinous line }\end{array}$ & $\begin{array}{l}\text { Uncinate process alignment-for } \\
\text { assessment of rotation deformity }\end{array}$ & $\begin{array}{l}\text { Lateral translation of vertebral body } \\
\text { Articular pillar alignment } \\
\text { Spinous process alignment for rotation }\end{array}$ \\
\hline Bone (fractures) & $\begin{array}{l}\text { Vertebral body compression-wedging } \\
\text { Coronal split fracture } \\
\text { Retropulsion } \\
\text { Articular pillar and articular process } \\
\quad \text { fracture } \\
\text { Spinous process fracture }\end{array}$ & $\begin{array}{l}\text { Comminution of vertebral body } \\
\text { Sagittal/coronal split fractures } \\
\text { Retropulsion } \\
\text { Pedicle and lamina fracture. } \\
\text { Transverse process fracture }\end{array}$ & $\begin{array}{l}\text { Sagittal split fracture Lateral cortical step of } \\
\text { vertebral body } \\
\text { Articular pillar } \\
\text { Transverse process } \\
\text { Any horizontally oriented fracture }\end{array}$ \\
\hline Measurement & $\begin{array}{l}\text { Interspinous widening } \\
\text { Interlaminar widening } \\
\text { Kyphotic angle }\end{array}$ & - & $\begin{array}{l}\text { Interpedicular widening } \\
\text { Interspinous widening (sagittal is preferred) }\end{array}$ \\
\hline Joint & $\begin{array}{l}\text { Intervertebral disc } \\
\text { Facet joints }\end{array}$ & $\begin{array}{l}\text { Uncinate process alignment for } \\
\text { rotation } \\
\text { Facet joint (sagittal is preferred) }\end{array}$ & $\begin{array}{l}\text { Intervertebral disc asymmetry in coronal plane- } \\
\text { suggestive of rotation and lateral flexion vector }\end{array}$ \\
\hline Ligaments & ALL, PLL, PLC injury_fingerprints & - & - \\
\hline
\end{tabular}

Volume rendered 3D images are useful in detecting- transverse process, spinous process fracture and detection of rotation of the vertebral body 


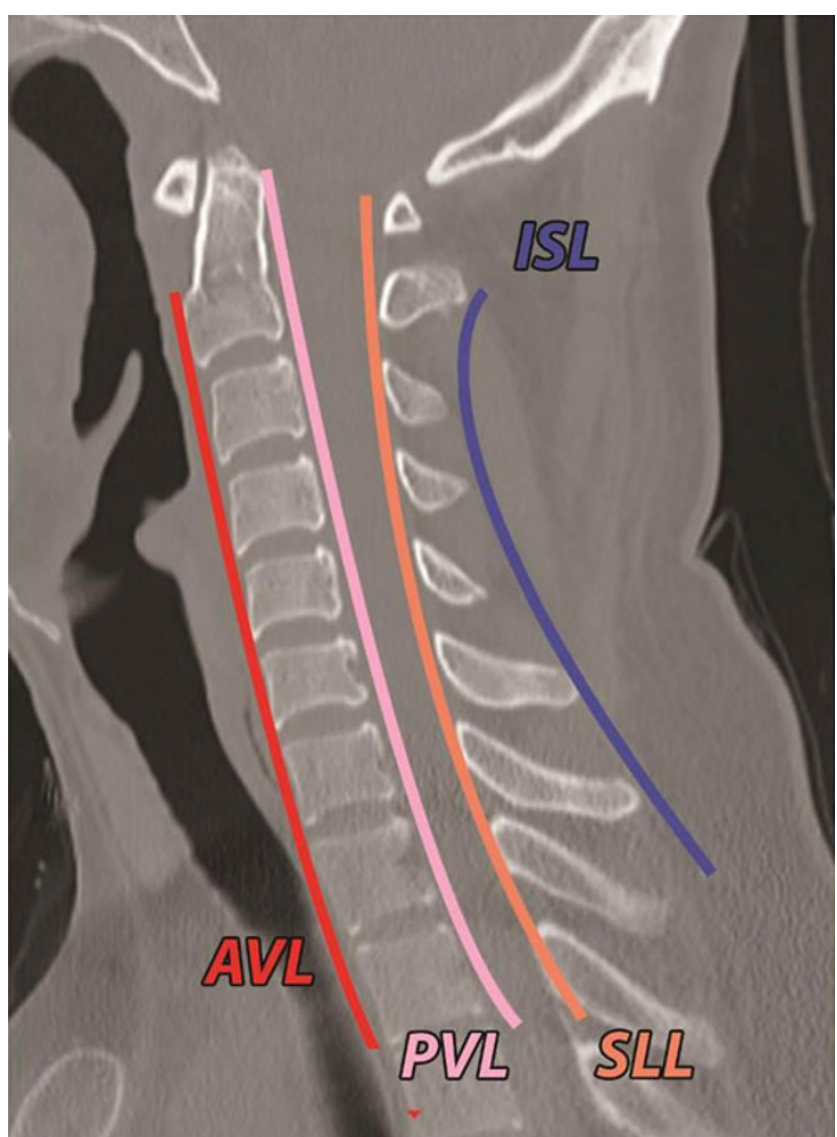

Fig. 5 Normal alignment of the spine as seen on mid-sagittal CT: anterior vertebral line $(A V L, r e d)$ - connecting the anterior cortices of the vertebrae; posterior vertebral line ( $P V L$, pink) - connecting the posterior cortices of the vertebrae; spinolaminar line (SLL, orange) - connecting the base of the spinous processes at the spinolaminar junction; interspinous line (ISS, blue - connecting the tips of the spinous processes. All of these lines should be gently curved, smooth and continuous

facet joints resemble a hamburger bun, with the flat portions articulating (Fig. 2) [20]. The uncinate processes of the lower vertebra lie lateral to the cranial vertebral body (Fig. 2) [21].

In the coronal plane, the lateral masses make bilateral smooth undulating margins. Spinous processes are in midline and any focal displacement of one spinous process in relation to the others is abnormal. Each of the bony components of the cervical vertebrae should be evaluated for fractures on all the available images in different planes and 3D reconstruction.

\section{CT measurements}

Quantification of the angulation, deformity, dislocations and measurement of prevertebral soft tissue to detect the abnormality or instability has become less relevant in modern practice, as MDCT shows the entire spectrum of the osseous and ligamentous disruption in multiple planes, which previously had to be inferred indirectly from the radiographs

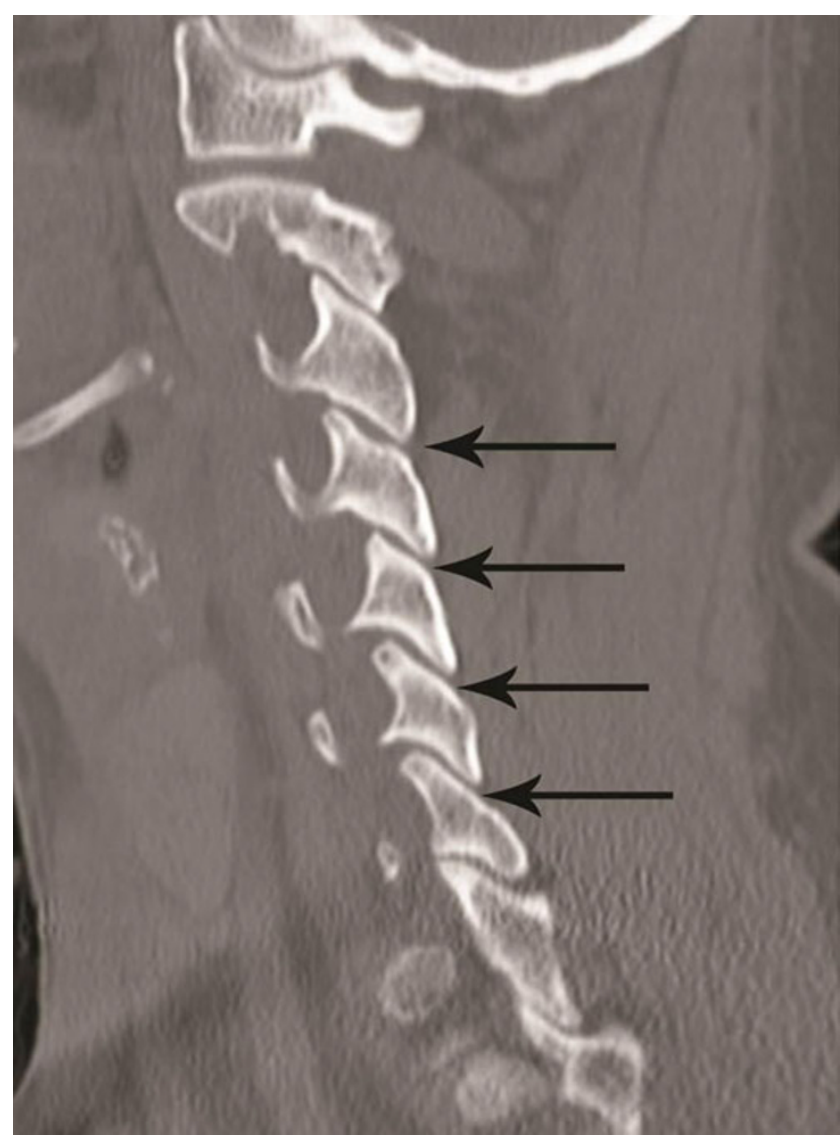

Fig. 6 Normal alignment of facet joints on parasagittal CT image (arrows). A facet joint is formed by the obliquely oriented rhomboid-shaped articular processes and overlaps like a roof shingle. The inferior articular process of the cranial vertebra is posterior to the superior articular process of the caudal vertebra. On sagittal images, a facet joint articular surface should be parallel, cranio-caudally symmetrical and congruent; the inferior articular facet should cover the entire articular surface on the superior articular facet below. The facet joint gap should be less than $2 \mathrm{~mm}$

previously. Moreover, these measurements have been shown to be inconsistent with limited interobserver reliability [22]. However, they can be measured on MDCT, which can be included in the checklist. To simplify and memorise different measurement parameters, Daffner and Harris [23] have popularised the "Rule of $2 \mathrm{~s}$ ". Interspinous, interlaminar and interpedicular distances, and also facet joint width, are abnormal if the difference of these parameters between the adjacent segments is more than $2 \mathrm{~mm}$. Interlaminar distance is more reliable and accurate than interspinous distance for diagnosing hyperflexion injury.

\section{Common injury patterns}

In this section the spectrum and pattern of injury produced by different forces on the cervical spine and their typical findings on CT scan is described. 


\section{Hyperflexion injury}

Hyperflexion is the most frequent type of injury vector encountered in patients with vertebral trauma. The injury spectrum includes compressive hyperflexion, vertical compression and distractive hyperflexion. The injury pattern resulting from these force vectors depends upon the centre of rotation, the fulcrum, which in turn is determined by the position of the head and neck at the time of injury. Additional vectors like rotation and lateral flexion can result in complex hyperflexion-rotation injury.

\section{Compressive hyperflexion}

This represents axial loading in which the motion segment is flexed and a compressive force is applied at the anterosuperior margin of the vertebral body, the centre of rotation remaining in front of the anterior column, resulting in compressive failure of the anterior column (Fig. 7). These injuries begin with anterior vertebral body wedging. With increasing flexion compression force, anterior vertebral body develops a vertically oriented fracture line in the coronal plane, separating a triangular anterior "teardrop" fragment from the posterior vertebral body. The shape of this teardrop fragment is commonly triangular, but a quadrangular variant has also been described [24]. With increasing force, tensile failure of the posterior disc, PLL and PLC occurs resulting in a highly unstable injury. This is often described as a flexion teardrop fracture, the most severe form of hyperflexion injury with fracture-dislocation of the involved motion segment (Fig. 8). In general, this type of injury has the highest rate of neurological injury of all cervical injuries. Since flexion teardrop fracture results in global disruption of all the supporting

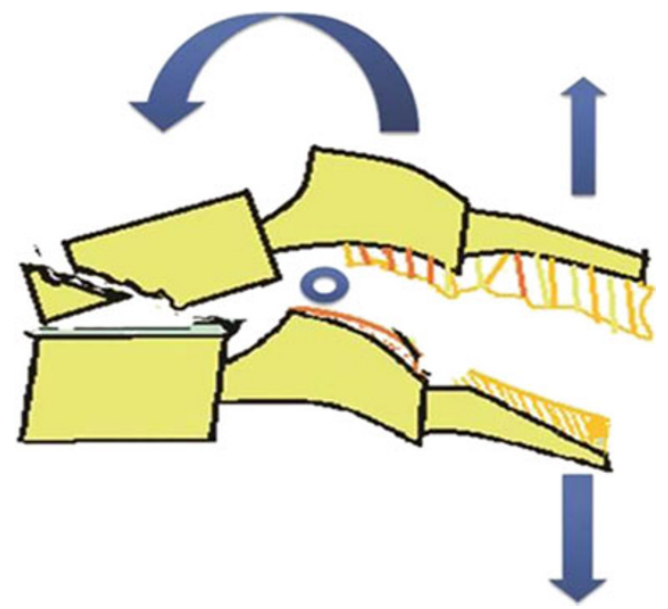

Fig. 7 Schematic showing a hyperflexion compression injury. Flexion vector with centre of rotation (blue hollow circle) is just behind the anterior column, resulting in a compressive force applied to the anterosuperior aspect of the vertebral body, causing a primary progressive compressive failure of anterior column. With increasing magnitude of force, posterior column distraction and tensile failure result

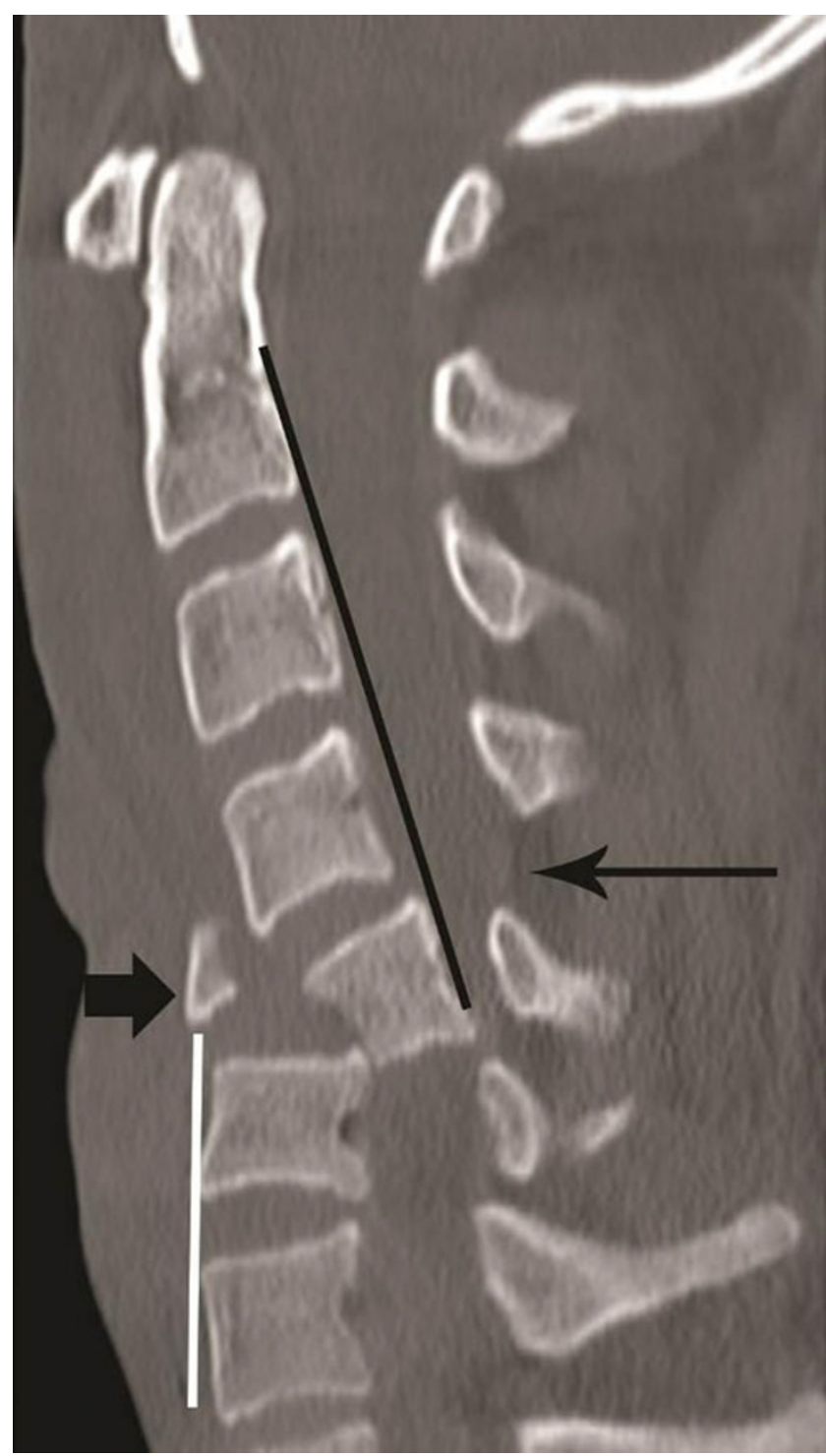

Fig. 8 Flexion teardrop fracture. Sagittal CT image of cervical spine in a young patient following vehicular accident shows wedging of $\mathrm{C} 5$ vertebral body with an oblique coronal fracture of the anterior third of the vertebral body, dividing the $\mathrm{C} 5$ in to a smaller anterior triangular fragment (short arrow) and a large posterior segment. Retrolisthesis of the C5 vertebral body on $\mathrm{C} 6$ behind the fracture line and retropulsed $\mathrm{C} 5$ keeping alignment with the cranial $\mathrm{C} 4$ vertebral body-suggested by noninterrupted posterior vertebral line (black line), while triangular fragment keeping alignment with the caudal C6 vertebra - suggested by noninterrupted anterior spinal line (white line). Distraction of posterior column is suggested by widening of interspinous/interlaminar space at C4 C5 (long arrow). Facet joint subluxation was seen on the parasagittal images (not shown)

ligaments, it is highly unstable and needs surgical stabilisation. CT characteristics of flexion teardrop fracture include [19, 25]: (1) oblique fracture in the coronal plane extending from anterior aspect of superior end plate to the inferior end plate - dividing the involved vertebral body into a small anterior triangular/quadrilateral fragment and a larger posterior body fragment; (2) posterior subluxation of the 


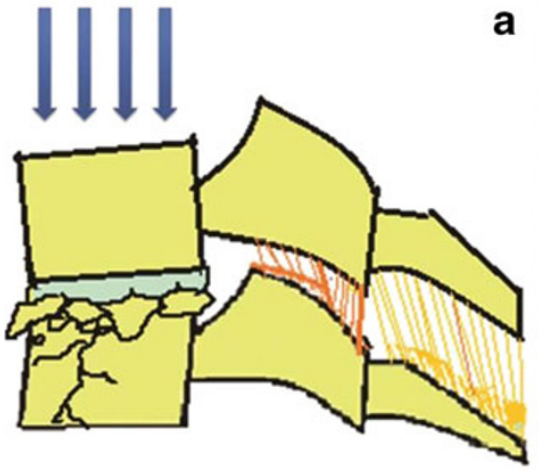

Fig. 9 Axial loading (vertical compression injury). a Schematic showing a vertical compression injury. Compressive force is exerted vertically to the spinal column with neck in the neutral position (30-degree flexion) at the time of injury, resulting in pure axial loading injury and compressive failure of the anterior column. The posterior column remains intact or

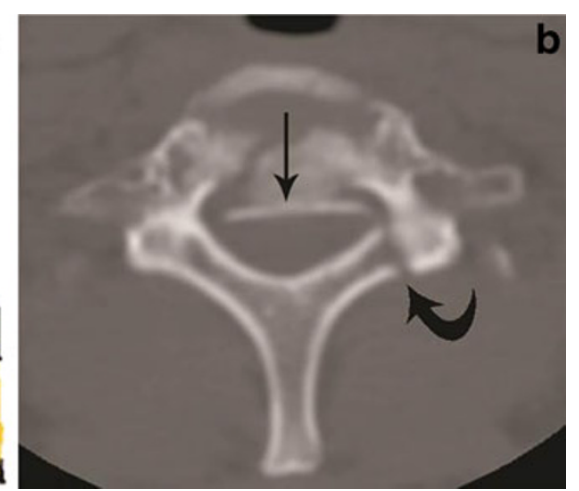

with increasing force fails in compression. b Axial CT shows marked comminution of the vertebral body with retropulsion of the fracture fragment from the posterior cortex in to the spinal canal (straight arrow) suggestive of burst fracture. Associated unilateral laminar fractures (curved arrow) are commonly seen remaining posterior vertebral body on the lower vertebradividing the spine into a caudal segment consisting of the anterior teardrop fragment and the lower vertebral body and, a cranial segment consisting of the retropulsed fractured vertebral body with the vertebrae above; (3) signs of posterior ligament complex injury (Fig. 8).

\section{Vertical compression/axial loading}

Axial loading is also referred to as vertical compression. This occurs when sufficient compressive force is exerted vertically through the spinal column (Fig. 9a). Injury from this mechanism often occurs with shallow diving, head-first tackling (rugby injury) or vehicular accidents with neck in neutral position (30 degrees of flexion). The vertebral bodies and intervertebral discs attempt to absorb the energy and literally burst, with horizontal spread of the fragments. Bone fragments are dispersed centrifugally in all directions, including into the spinal canal, often resulting in catastrophic neural damage. Pure axial loading forces lead to a symmetrical loss of vertebral body height, with little kyphosis or translation.

On CT, minor vertical compression results in central cupping of vertebral end plates and/or sagittal/coronal split fractures. With increasing force, a typical burst fracture shows vertebral body height loss with comminution of vertebral body and centrifugal displacement of the fracture fragments; fracture lines extending to the posterior cortex with retropulsed fragments (Figs. 9b and 10) [23].
Fig. 10 Burst fracture. a Midsagittal CT image showing a comminuted fracture of $\mathrm{C} 7$ with nearly symmetrical loss of vertebral body height with extension of the fracture to the posterior cortex and retropulsion of fragment from the posterospuerior cortex of $\mathrm{C} 7$ (white arrow) - suggestive of a burst fracture. Vertebral body comminution is better seen on axial images as shown in Fig. 9b. b Coronal CT image showing a vertical split fracture of $\mathrm{C} 6$ and C7 (black arrows). These fractures are oriented in the sagittal plane, hence best seen on coronal images and highly suggestive of axial loading injury
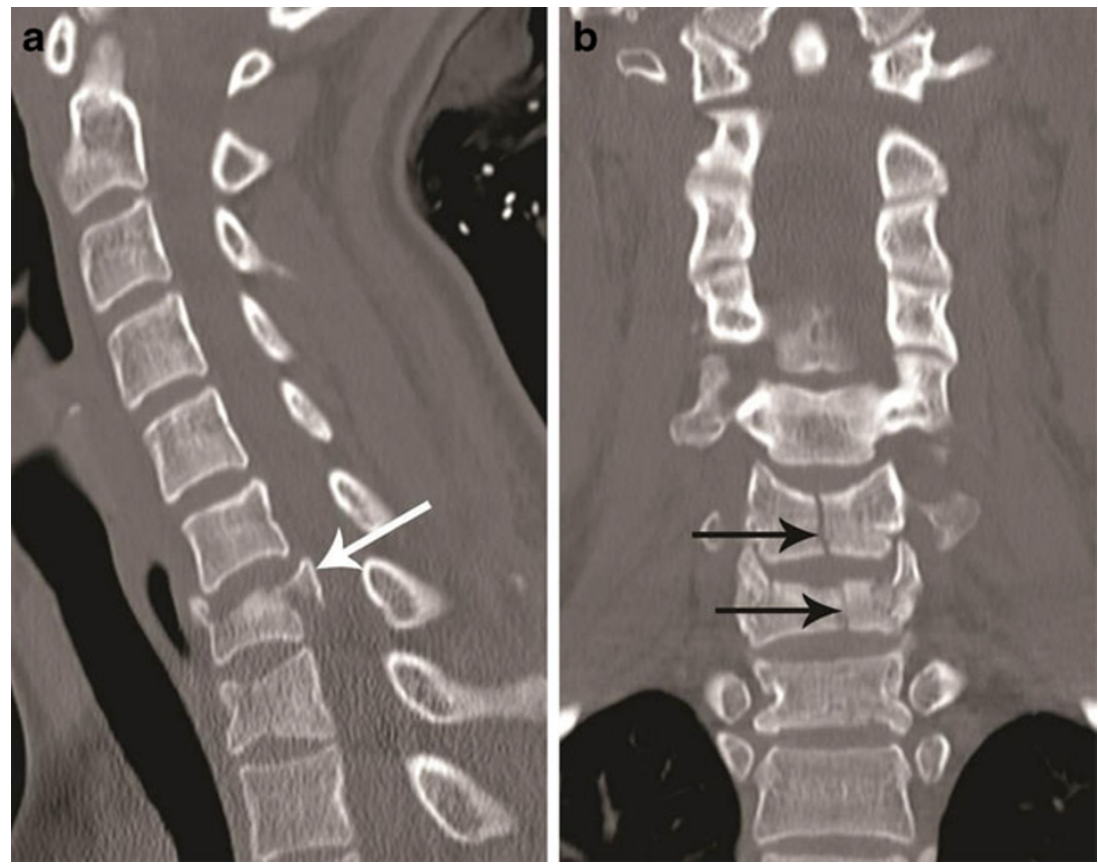


\section{Distractive hyperflexion}

The centre of rotation of this hyperflexion injury is thought to occur anterior to the vertebral body with neck in flexion, resulting in primary progressive tensile failure of posterior elements (Fig. 11) [19]. A minor compressive vector is also frequently present, resulting in fracture of the vertebral end plate. Flexion-distraction injuries represent a continuum of ligamentous injuries, ranging from sprain to complete tear of the PLC. Corresponding ligamentous disruption progresses from posterior to anterior, beginning with disruption of the supraspinous ligament, interspinous ligaments, facet capsular ligaments and ligamentum flava, in that sequence. With more severe distractive force, progressive failure of the anterior ligaments might also occur. Minor injuries of PLC can easily be missed and may result in delayed instability if overlooked on initial CT examinations.

CT features of PLC injury include: interspinous widening, interlaminar widening; facet joint distraction subluxation or dislocation, widened posterior disc space, focal kyphosis and anterior subluxation of the vertebral bodies (Figs. 12 and 13) [26]. The facet joint injury spectrum of hyperflexion distraction injury with progressive severity includes: facet joint distraction, subluxation and dislocation (Fig. 13). "Locked", "perched" and "jumped" facet joints are alternative terminologies used in the radiology and surgery literature for the dislocated facet joint and should preferably be replaced by "facet joint dislocation". Facet joint dislocation can be a purely ligamentous injury when predominant force is distraction, and this results in dislocation without fracture of the facets. In the presence of a shear or rotation vector, facet joint dislocation is accompanied by fracture of articular processes.

Bilateral facet dislocation is the most severe injury of the flexion-distraction spectrum, which usually results in

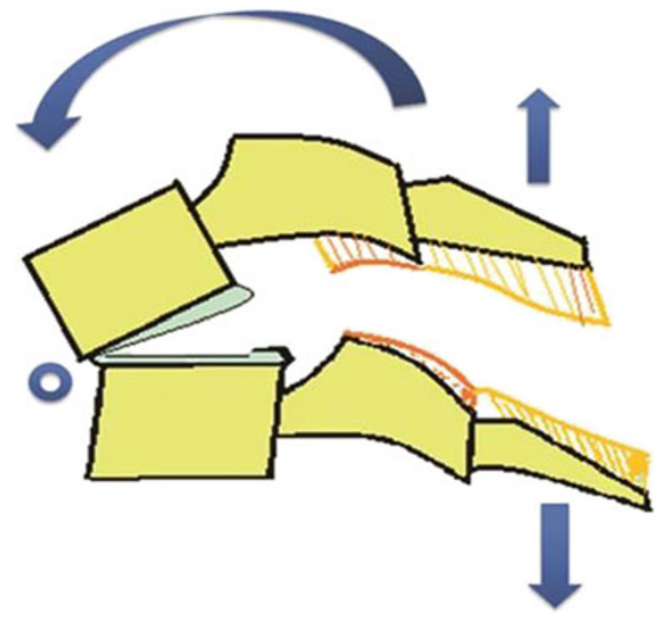

Fig. 11 Schematic showing hyperflexion distraction injury. Flexion vector with centre of rotation (blue hollow circle) anterior to the anterior column, resulting in posterior column distraction with progressive tensile failure of the posterior column

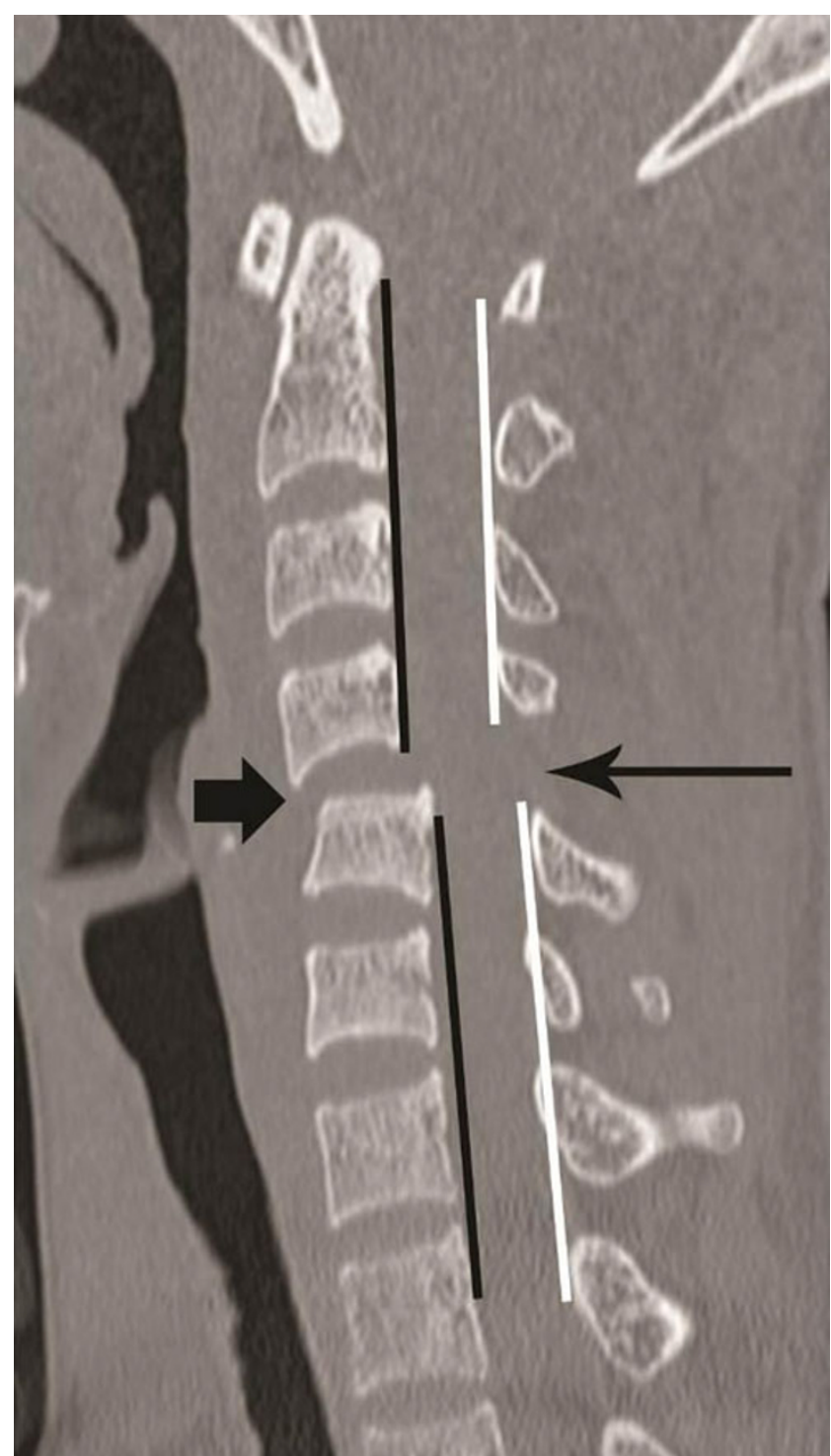

Fig. 12 Hyperflexion distraction injury. Mid-sagittal CT image of the cervical spine shows focal kyphosis with posterior disc space widening at C4-C5 (short arrow). Mild anterolisthesis of C4 over C5 is seen suggested by the disrupted posterior vertebral line (black lines). The spinolaminar line is also disrupted with at $\mathrm{C} 4-\mathrm{C} 5$ with anterior displacement of $\mathrm{C} 4$ spinolaminar junction (white lines). Widening of the $\mathrm{C} 4-\mathrm{C} 5$ interlaminar/interspinous space (long arrow) is noted. Combination of this pattern of injury is highly suggestive of hyperflexion distraction injury and the facet joint should be carefully evaluated on lateral parasagittal images for possible distraction, subluxation and dislocation (shown in Fig. 13)

profound neural insult [27]. Bilateral facet joint dislocation results in complete disruption of facet joint capsule and PLC in all cases. PLL disruption is also described in 40-100\% of cases of bilateral facet joint dislocation [27, 28]. Traumatic disc herniation with posterior annulus disruption is described in $56 \%$ of unilateral and $82.5 \%$ of bilateral facet dislocations [27]. Disc herniation is relevant in the management of these injuries and should be confirmed by magnetic resonance 

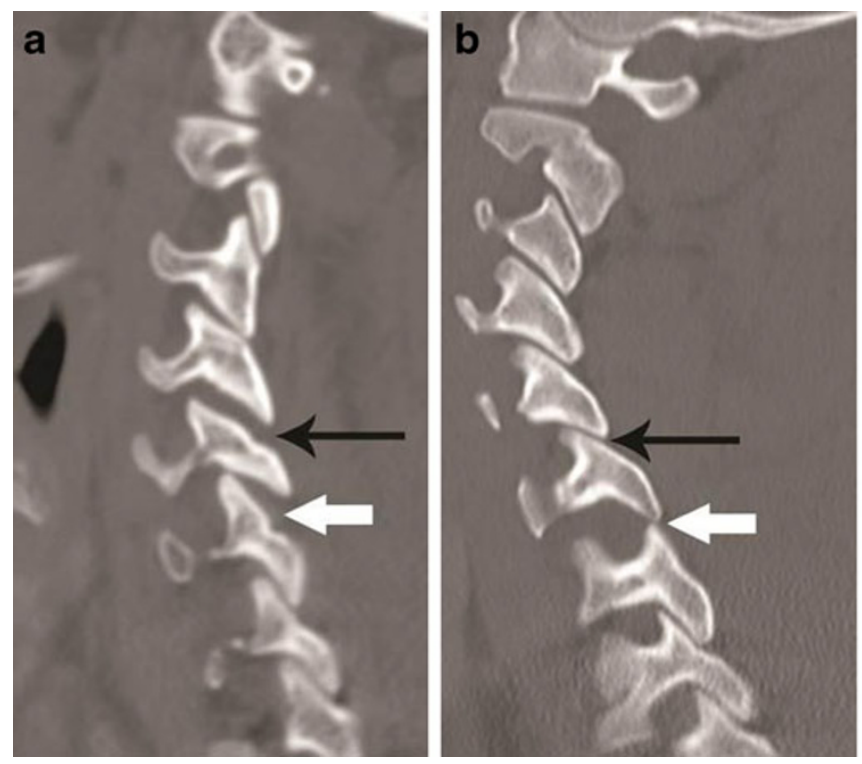

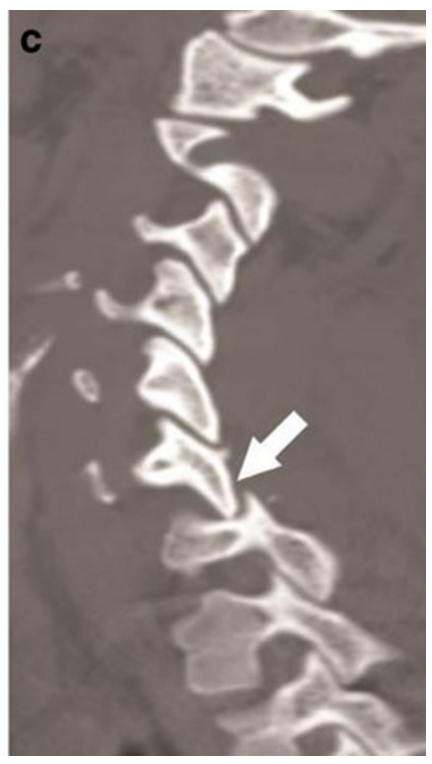

Fig. 13 Facet joint injury spectrum resulting from hyperflexion distraction. Parasagittal CT images. a The $\mathrm{C} 4-\mathrm{C} 5$ facet joint shows diffuse widening - diastasis (black arrow), and the C5-C6 facet joint shows focal anterior widening (white arrow), suggestive of distraction injury and partial disruption of facet joint capsule. Articular surfaces are congruent and no uncovering of the inferior articular process noted at any of the injured levels. b C5-C6 facet joint subluxation (black arrow), suggested by non-congruent articular surfaces of the facet joint with anterosuperior displacement of the inferior articular process of $\mathrm{C} 5$, resulting in partial uncovering of the superior articular surface of C6. However, some apposition of articular surface is still intact. C6-C7 facet joint dislocation (white arrow) suggested by anterior and superior translation of inferior articular process of $\mathrm{C} 6$ resting on the top of the $\mathrm{C} 7$ articular process, resulting in complete loss of articular apposition and uncovering of $\mathrm{C} 7$ articular facet. A facet joint injury as seen at $\mathrm{C} 6-\mathrm{C} 7$ is also named as a "perched facet". c C6-C7 facet joint dislocation with further anterior translation of the inferior articular process (white arrow), now resting anterior to the $\mathrm{C} 7$ articular pillar. This injury is also called a "locked" or "jumped facet" imaging (MRI) before the reduction or stabilisation of facet joint dislocation is attempted.

Unilateral facet joint dislocation is a hyperflexion injury when the fulcrum is off-centre. This results in simultaneous hyperflexion and axial rotation with asymmetric injury leading to asymmetrical tensile failure of posterior column and unilateral facet joint injury with fractures, subluxation and dislocation [29].

CT differentiation of unilateral versus bilateral facet joint dislocation is best appreciated in the sagittal plane (Fig. 14) $[19,30]$. Though axial sections are not very useful to diagnose facet joint dislocation when isotropic sagittal reconstruction is possible, there are several well-described signs of diagnosing facet joint dislocation on axial images in the radiology literature, including the naked facet sign [31], the reverse "hamburger bun" [20] and the "headphones sign" (Fig. 15) [21]. A fracture of the posteroinferior cortex of the rotated vertebral body is frequently seen in patients with unilateral or bilateral facet joint dislocation. It is believed to be secondary to an avulsion of the PLL or the posterior annulus from the discovertebral junction [32].

Unilateral facet dislocation is mistakenly believed and reported as a stable injury in the literature; in reality it is a highly unstable injury that needs surgical stabilisation. Presence of an articular process in patients with facet joint dislocation is of surgical significance and should be reported. Unilateral facet joint dislocation was associated with fracture of articular processes in approximately $75 \%$ of cases [32]. Presence of markedly comminuted fracture with displaced fracture might preclude a closed reduction of these injuries. Pre-operative MRI is recommended for the treatment decision in patients with bilateral and unilateral facet joint dislocation to look for intervertebral disc disruption. This information has huge therapeutic implication; because in the absence of disc disruption, these injuries are best treated by the posterior approach; in the event of disc damage, they need anterior decompression and stabilisation with fusion across the disc.

\section{Hyperextension injury}

Hyperextension injury results when there is extreme extension of the spinal column, such as in a fall or vehicular collisions when the chin, forehead or face strikes an immovable object-like the dashboard, steering wheel or ground. Hyperextension injuries are observed in younger patients after high-energy trauma or in older patients with spondylotic or ankylosed spine after seemingly trivial injuries.

Hyperextension injuries are biomechanically the opposite of hyperflexion injury, resulting in tensile failure of the 


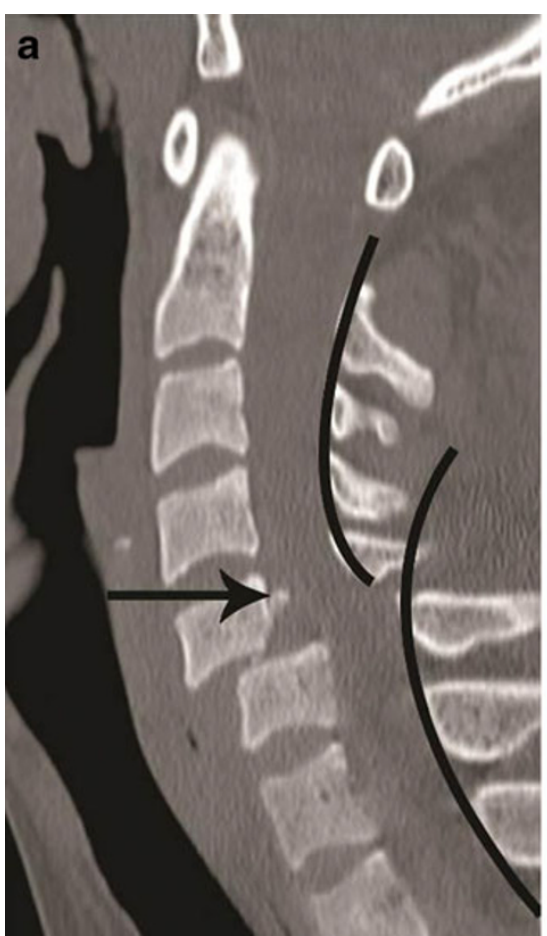

Fig. 14 Bilateral versus unilateral facet joint dislocation. a Mid-sagittal CT image shows anterior translation of $\mathrm{C} 5$ over C6 by more than $50 \%$ anteroposterior width of the $\mathrm{C} 6$, highly suggestive of bilateral facet joint dislocation, which was confirmed on parasagittal images (not shown). Large triangular bony fragment is noted at the posteroinferior corner of C5 (arrow) with diffuse loss of C5-C6 intervertebral disc space. b Mid sagittal CT image shows anterior translation of $\mathrm{C} 4$ over C5 by less than $50 \%$ anteroposterior width of C5 (approximately $25 \%$ ), highly suggestive of unilateral facet joint dislocation, which was confirmed on

anterior column and compressive failure of the posterior column. The Hyperextension injury spectrum includes both compressive hyperextension and distractive hyperextension, depending upon the fulcrum at the time of injury. Additional vectors like rotation and lateral flexion can result in complex hyperextension-rotation injury (Fig. 16).

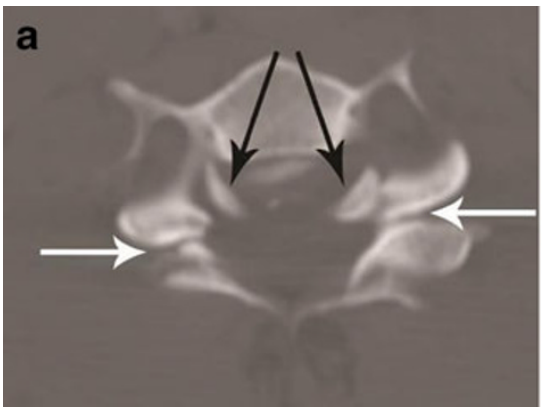

Fig. 15 Bilateral versus unilateral facet joint dislocation. a Axial CT of the $\mathrm{C} 5$ - $\mathrm{C} 6$ facet joint shows bilateral facet joint dislocation, suggested by reversal of the normal facet relationship, with convex surfaces opposing each other - called the "reverse hamburger sign" (white arrows). Loss of concentric relationship of the uncinate processes (black arrows) to the superior vertebral body — called the "positive headphone sign". b Axial

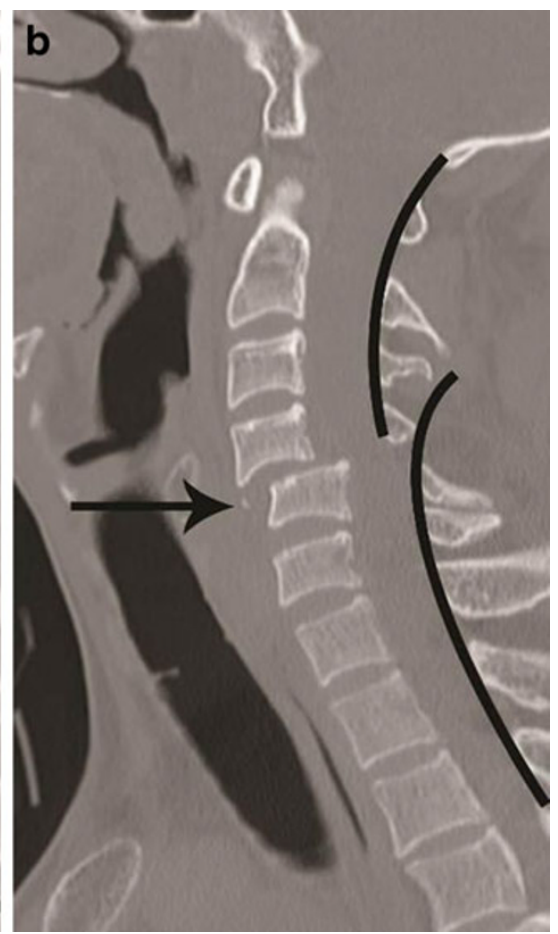

parasagittal images (not shown). Small triangular bony fragment is noted at the anteroinferior corner of $\mathrm{C} 4$ (arrow) with loss of C4-C5 disc space. Disruption of spinolaminar line (black curved lines) at the level of anterolisthesis with anterior displacement of the same vertebra and lamina (C5 in a and C4 in b) is highly suggestive of hyperflexion injury. Presence of small avulsion fragments at the discovertebral junction with loss of intervertebral disc height is associated with disc injury, which needs further evaluation with MRI

\section{Hyperextension compression}

It represents axial load injuries in which the motion segment is extended and a compressive force is applied to the posterior motion segment, the neural arch (Fig. 16). The spectrum of injury in this group includes unilateral or bilateral fractures of

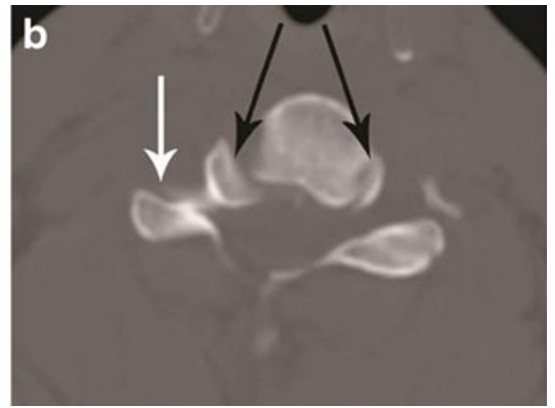

CT of the C4-C5 facet joint shows unilateral right-sided facet joint dislocation, suggested by a "naked facet" (white arrow) - due to absence of the opposing facet joint articular process because of dislocation. Loss of concentric arrangement of the right uncinate process (black arrows) due to rotation of vertebral body to the undislocated left side, resulting in unilateral positive "headphone sign"- suggesting rotational deformity 


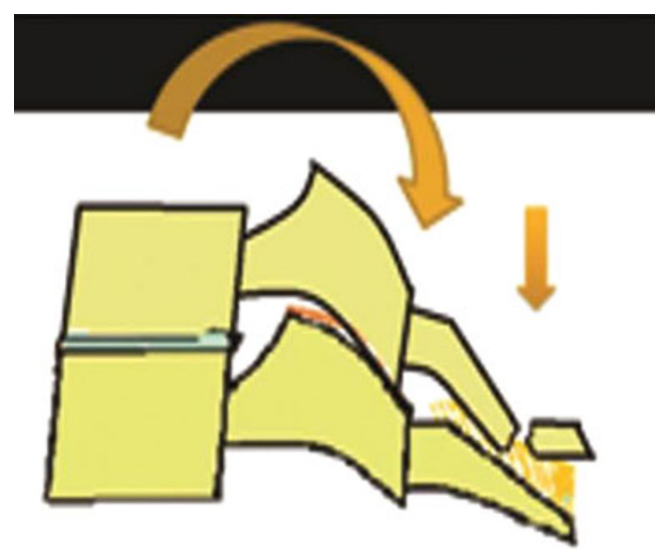

Fig. 16 Schematic showing hyperextension compression injury. Extension vector with centre of rotation is behind the anterior column, resulting in axial loading force applied to the posterior column, resulting in compressive failure of the posterior column. With increasing magnitude of force, anterior column distraction and tensile failure might occur

the neural arch, including fractures of the lateral mass, laminae or articular pillars. Fractures can frequently be comminuted and occur at multiple contiguous levels (Fig. 17). Traumatic anterior spondylolisthesis occurs if there is bilateral pedicular or lateral mass fracture. This injury is commonly misdiagnosed as hyperflexion injury and spinolaminar line is very useful in differentiating between them (Fig. 18). The spinolaminar line is not interrupted at the level of anterolisthesis in hyperextension injury [23].

\section{Hyperextension rotation}

Typical injury results from eccentric extension force on the forehead or upper face with the head rotated, resulting in rotation and axial loading injury on the side of rotation. This causes an asymmetric, hyperextension compression injury of the posterior column, resulting in asymmetric or unilateral fractures of articular pillars or processes. Simultaneous fracture of the ipsilateral pedicle and lamina results in traumatic isolation of the cervical articular pillar (Fig. 19). The proposed injury mechanism is hyperextension rotation [33] and hyperflexion rotation [34]. Traumatic isolation of cervical articular pillar can potentially lead to rotational instability of the facet above and below the involved articular pillar and displaced fractures might need surgical stabilisation.

\section{Hyperextension distraction}

The centre of rotation of hyperextension distraction is posterior to the vertebral column with neck in extension, resulting in primary progressive tensile failure of the anterior column (Fig. 20). They are predominantly ligamentous disruptions that progress from anterior to posterior, beginning with the anterior longitudinal ligament. Tensile failure of the anterior column may be accompanied by compressive failure of the posterior column.

These injuries are very common in individuals with degenerated or ankylosed spines - as seen in ankylosing
Fig. 17 Hyperextension compression injury. a Parasagittal CT image shows C6, C7 articular pillar and process comminuted fracture with vertical orientation (black arrows). Focal anterior widening of C4-C5 facet joint (white arrow) is a characteristic feature of hyperextension injury. b Coronal CT image from the articular pillar in a different patient shows left C5 articular pillar fracture with vertical orientation and comminution (black arrow)
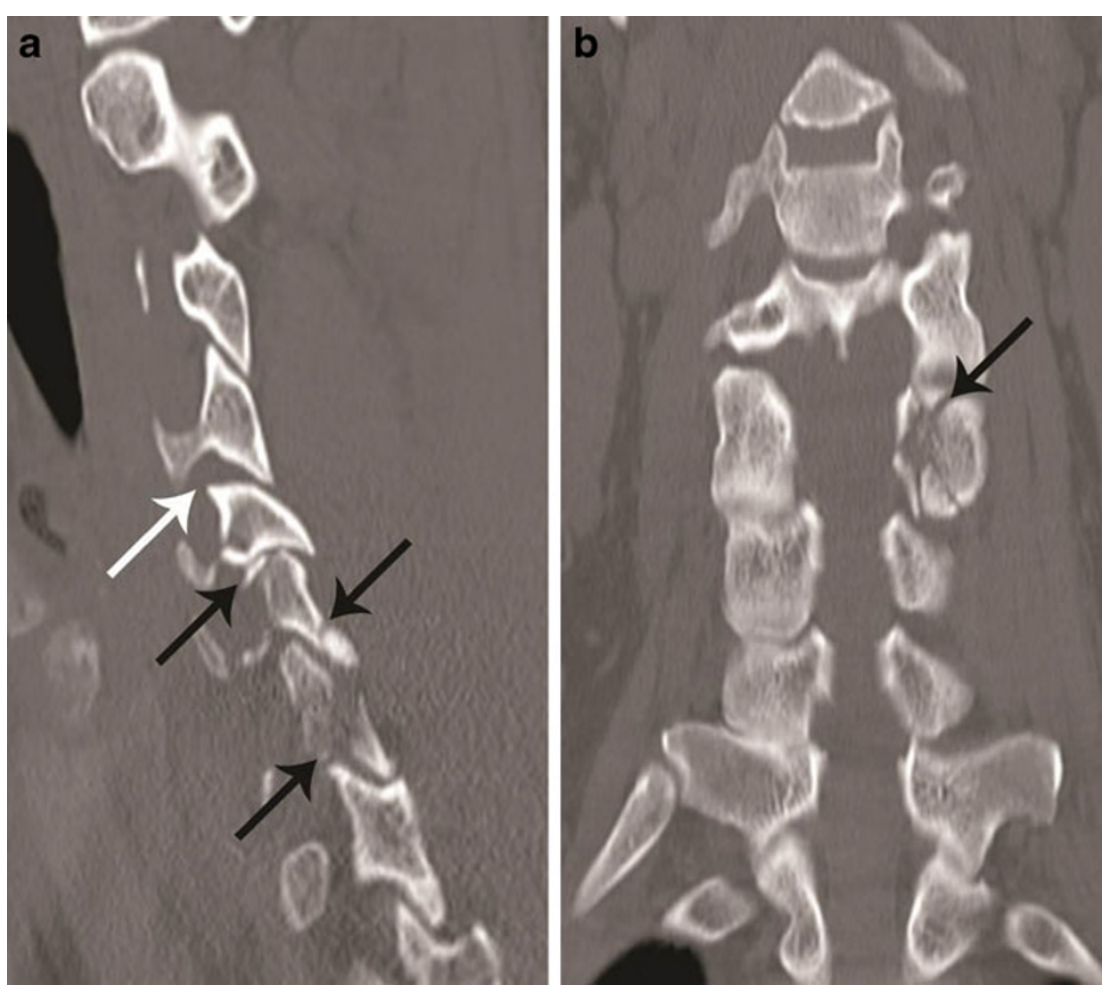
Fig. 18 Hyperextension compression with traumatic spondylolisthesis. a Mid-sagittal $\mathrm{CT}$ image shows anterior listhesis of $\mathrm{C} 7$ over D1 (white arrow). This could result from hyperflexion distraction or, rarely, hyperextension injury. The spinolaminar line is continuous at the level of anterior translation, which suggests a hyperextension injury vector. b Left parasagittal image from the facet joint shows a vertically oriented fracture through the left pars interarticularis of $\mathrm{C} 7$ (black arrow) with impaction of the tip of the inferior articular process of C6 in the fracture gap-highly suggestive of hyperextension injury. Similar pars interarticularis fracture was also seen on the right side of C7 (not shown)
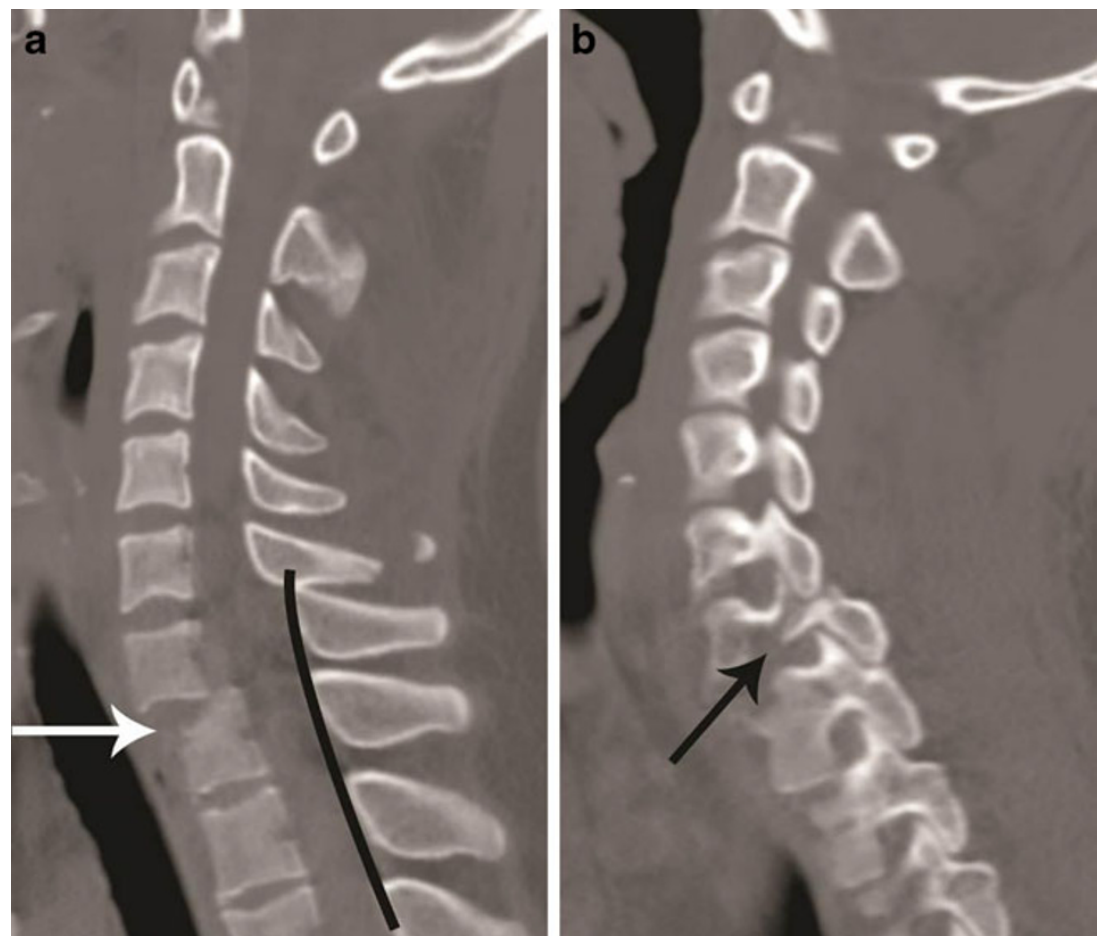

spondylitis and diffuse hypertrophic skeletal hyperosteosis (DISH) - even with relatively minor trauma [35].

CT in hyperextension distraction may show subtle abnormality, which can easily be overlooked due to the predominant soft tissue and ligamentous nature of the injury. Prevertebral soft tissue thickening can sometimes be the only clue to these injuries. Anterior disc space widening is the imaging hallmark of hyperextension distraction injury and results from ALL and anterior annulus rupture (Fig. 21) [33]. Tensile forces through the intact ALL may cause an avulsion fracture of the anterior body (an extension "teardrop" fracture) or fracture of an

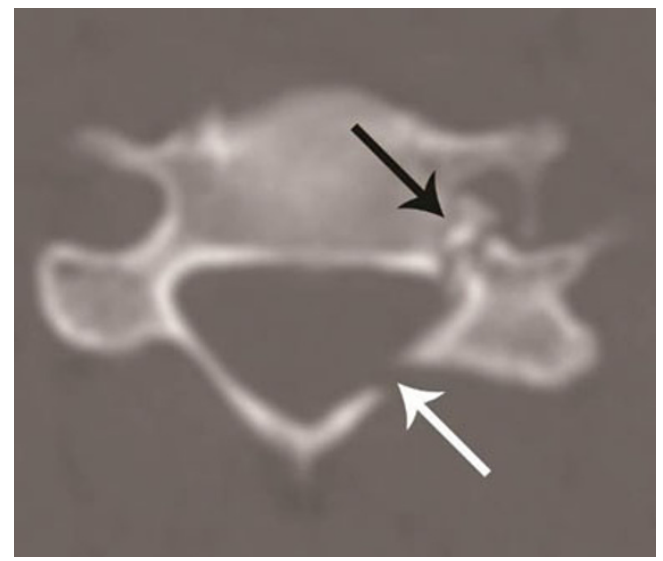

Fig. 19 Pediculolaminar separation. Axial CT image shows simultaneous fracture of left lamina (white arrow) and pedicle (black arrow) of the $\mathrm{C} 5$ vertebra, resulting in pediculolaminar separation. Extension of the fracture line to the left transverse foramen and presence of fracture fragment within the transverse foramen seen, raising suspicion for the left vertebral artery injury osteophyte or syndesmophyte overlying the disc space. CT scan shows extension teardrop fracture as a triangular fragment from the anteroinferior vertebral body or uncommonly from anterosuperior vertebral body on sagittal images (Fig. 22). In elderly patients with degenerated spines, $\mathrm{C} 2$ is most commonly involved, while in young patients the lower cervical spine is involved [33]. Facet joint injury resulting from hyperextension injury produces Vshaped facet joints that are wide anteriorly and tapered posteriorly (Fig. 17).

Increasing hyperextension force results in hyperextension dislocation - transient posterior dislocation of the cranial vertebra over the caudal one-resulting in disruption of ALL,

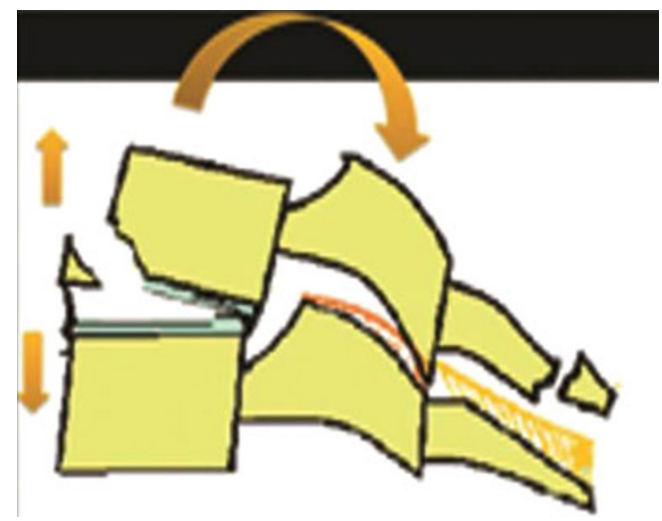

Fig. 20 Schematic showing hyperextension distraction injury. Extension vector with centre of rotation posterior to the vertebral column, resulting in distraction and tensile failure of the anterior column. Increasing the magnitude of the force results in hyperextension dislocation 


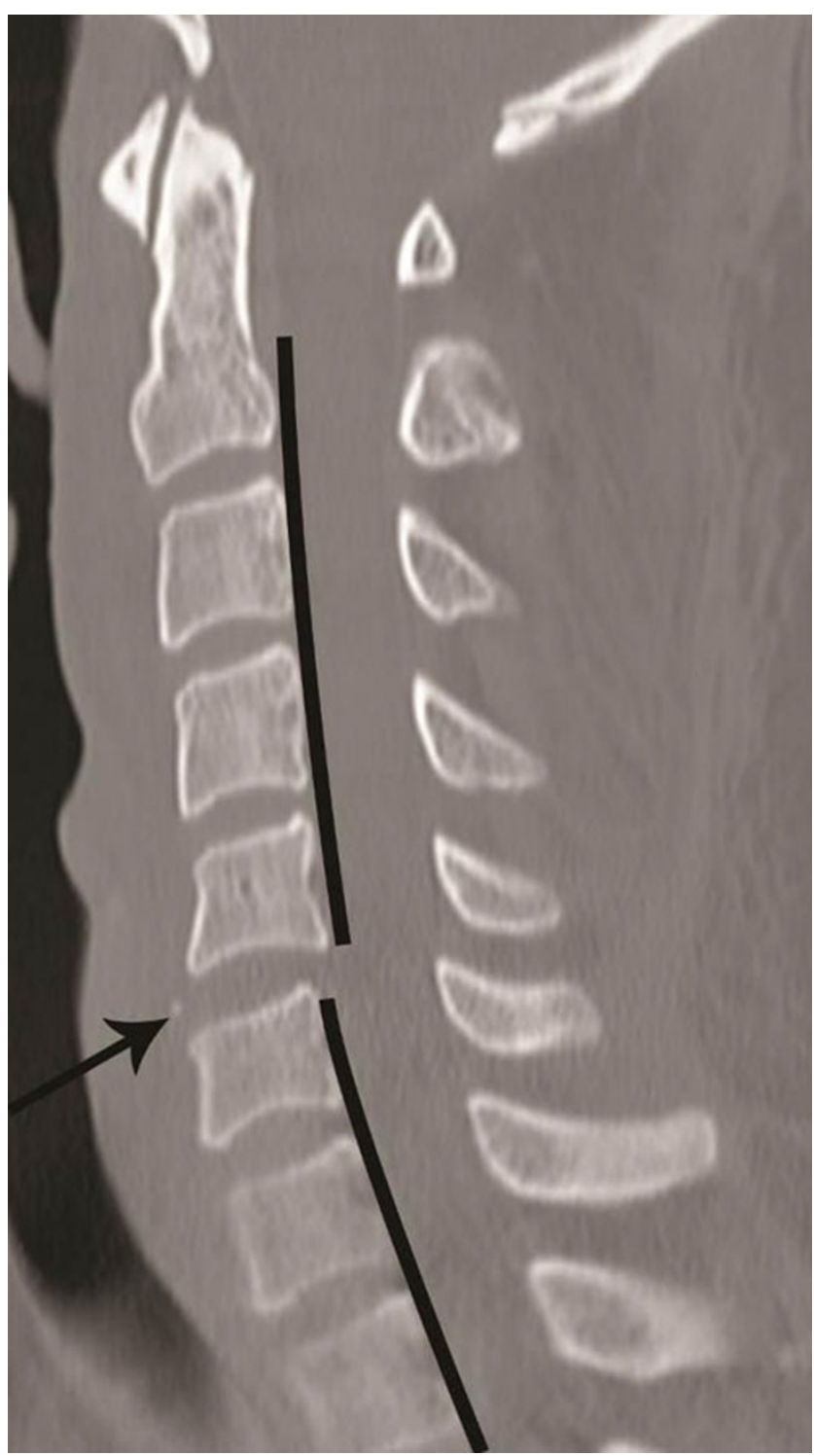

Fig. 21 Hyperextension distraction with dislocation. Mid-sagittal CT image shows the significant prevertebral soft tissue swelling and subtle anterior widening of the $\mathrm{C} 5-\mathrm{C} 6$ disc space - a hallmark of hyperextension distraction injury. A small avulsion fracture (arrow) is noted at C5C6. Mild retrolisthesis of $\mathrm{C} 5$ on $\mathrm{C} 6$ vertebral body suggested by disrupted posterior vertebral line (black lines) - suggestive of hyperextension dislocation

anterior annulus, disc, posterior annulus and PLL. The hyperextension dislocation injury is often accompanied by major neurological deficits, typically a central cord syndrome. Hyperextension-dislocation injuries sometimes produces minimal imaging features on radiographs or CT - as the posterior dislocation is transient and may be completely reduced spontaneously when the force is removed. It should be suspected in patients with lower facial trauma and central cord syndrome. The hallmark of distraction injury is widening of the anterior disc space and diffuse prevertebral soft tissue swelling. Some degree of retrolisthesis may also be present suggested by disrupted posterior vertebral line (Fig. 21). Less common

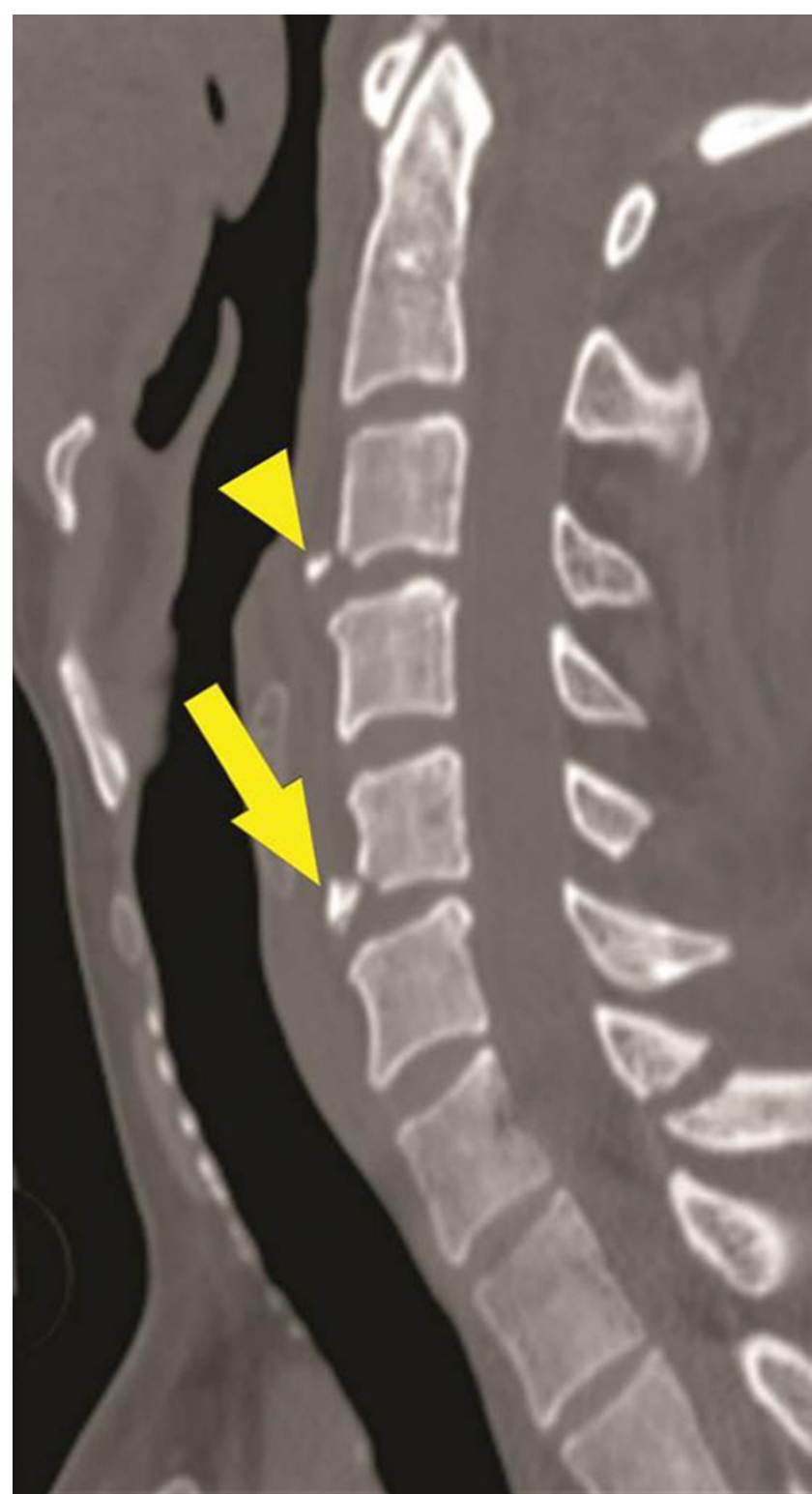

Fig. 22 Hyperextension teardrop. Sagittal CT image shows small triangular avulsion fractures at the anteroinferior end plate of $\mathrm{C} 3$ (arrowhead) and C5 (arrow) without significant prevertebral soft tissue lesion. The triangular fragment at C5 is taller than wider, suggestive of hyperextension teardrop than hyperextension dislocation

CT indicators include: disc vacuum phenomenon and an avulsion fracture of the anteroinferior margin of the involved vertebra caused by avulsion due to the intact Sharpey's fibres (Fig. 23) [23]. Horizontal fractures through the vertebral body or fused disc space might occur in ankylosed spines. MRI is indicated to further diagnose the extent of discoligamentous injuries and spinal cord compression/injury in patients with clinically or radiologically suspected hyperextension distraction injuries. MRI is complementary to CT in these cases and should be done in elderly or ankylosed spine with even trivial trauma and in the presence of any neurological deficit. 


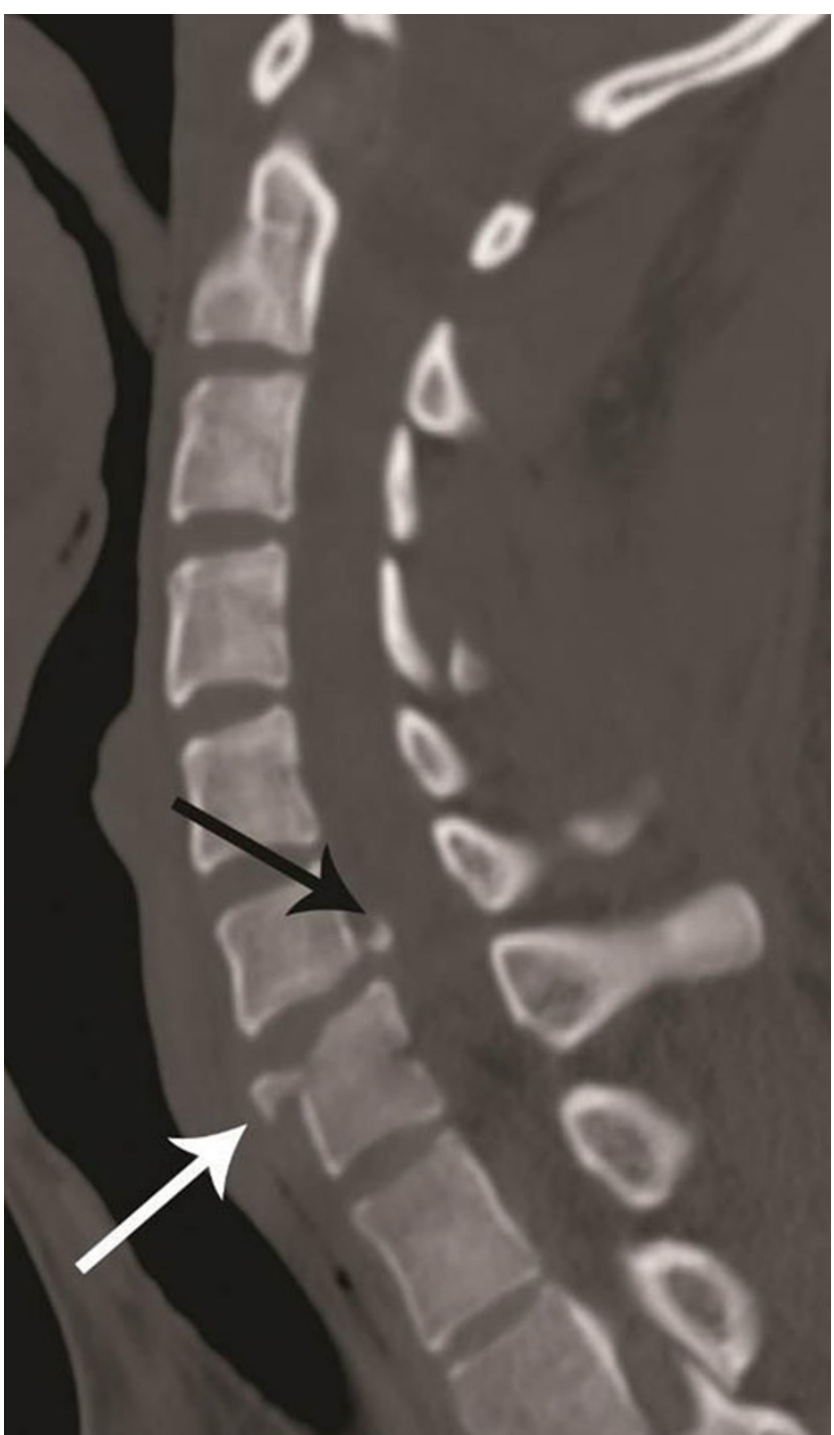

Fig. 23 Avulsion fracture in hyperextension dislocation. Sagittal CT image shows an avulsion fracture at the anterosuperior end plate of $\mathrm{C} 7$ (white arrow), with the transverse diameter wider than the vertical diameter. Avulsion of the posteroinferior corner of the C6 vertebral body is also seen (black arrow), which suggests avulsion of the posterior annulus or PLL

\section{Rotation injury}

Rotary injuries are the result of rotational or torsion force applied about the long axis of the vertebral column. Malalignment of spinous process on the coronal plane (Fig. 24a) is the most commonly used sign to imply the rotation vector; however, on $\mathrm{CT}$, asymmetry of the uncinate process as seen on axial images is one of the most accurate and reliable indicator of the rotation vector (Fig. 15b) [21]. Other useful signs suggestive of rotation injury include: asymmetric disc space with rotated vertebral body in coronal plane and rotation of the fracture fragments. Rotational deformity is well depicted on 3D volume rendered image (Fig. 24b). Presence of rotation vector suggests more severe violence with possible ligamentous disruption.

\section{Lateral flexion injury}

Lateral flexion injuries are unusual, rarely isolated and most commonly occur in combination with hyperextension and are secondary to a rotational component at the time of impact. Asymmetrical compression of vertebral body suggests lateral flexion injury. Unilateral transverse process and uncinate process fracture typically results from lateral flexion injury. Although spinal cord injury is unusual, since the mechanism is thought to involve violent lateral flexion of the neck, nerve root injuries, including root avulsions and brachial plexus injuries, may occur.

\section{Injury morphology suggesting ligamentous injury}

Although osseous injury to the cervical spine demands most of the attention, ligamentous integrity is equally important for the spine stability. Ligamentous disruption can occur in the absence of osseous abnormality, particularly with distraction injury vectors. Missed ligamentous injury can lead to significant morbidity and delayed instability, leading to persistent pain, kyphosis, delayed vertebral dislocation and neurological deficit.

Ligaments are not directly visualised on CT unlike on MRI. However, ligamentous failure can be inferred from CT by the presence of abnormal angulation, translation-dislocation and distraction injury morphology on CT (Table 3). Presence of normal CT is very reliable in excluding clinically significant unstable ligamentous injury [36]. MRI is traditionally used to diagnose suspected ligamentous injury with normal or equivocal CT.

\section{Look-alike injuries and usefulness of biomechanics in differentiation}

Different biomechanical forces and injury vectors can produce "look-alike" injury morphology on CT. It is important to distinguish them, as these lesions may have different clinical implications.

The previous sections described the CT differentiation of unilateral versus bilateral facet joint dislocation and hyperextension distraction versus hyperextension dislocation injury. Important differentiating features between a burst versus flexion teardrop injury and flexion versus extension teardrop injury are explained in Tables 4 and 5 respectively.

To predict vascular injury and the need for $C T$ angiography: The reported incidence of vertebral artery injury 
Fig. 24 Rotational vector and deformity. a Posterior coronal CT image shows focal deviation of the $\mathrm{C} 5$ spinous process (arrow) suggested by the interspinous line not passing through the rotated C5 spinous process. b Threedimensional volume rendered coronal image shows rotational deformity of the C5/C6 vertebrae
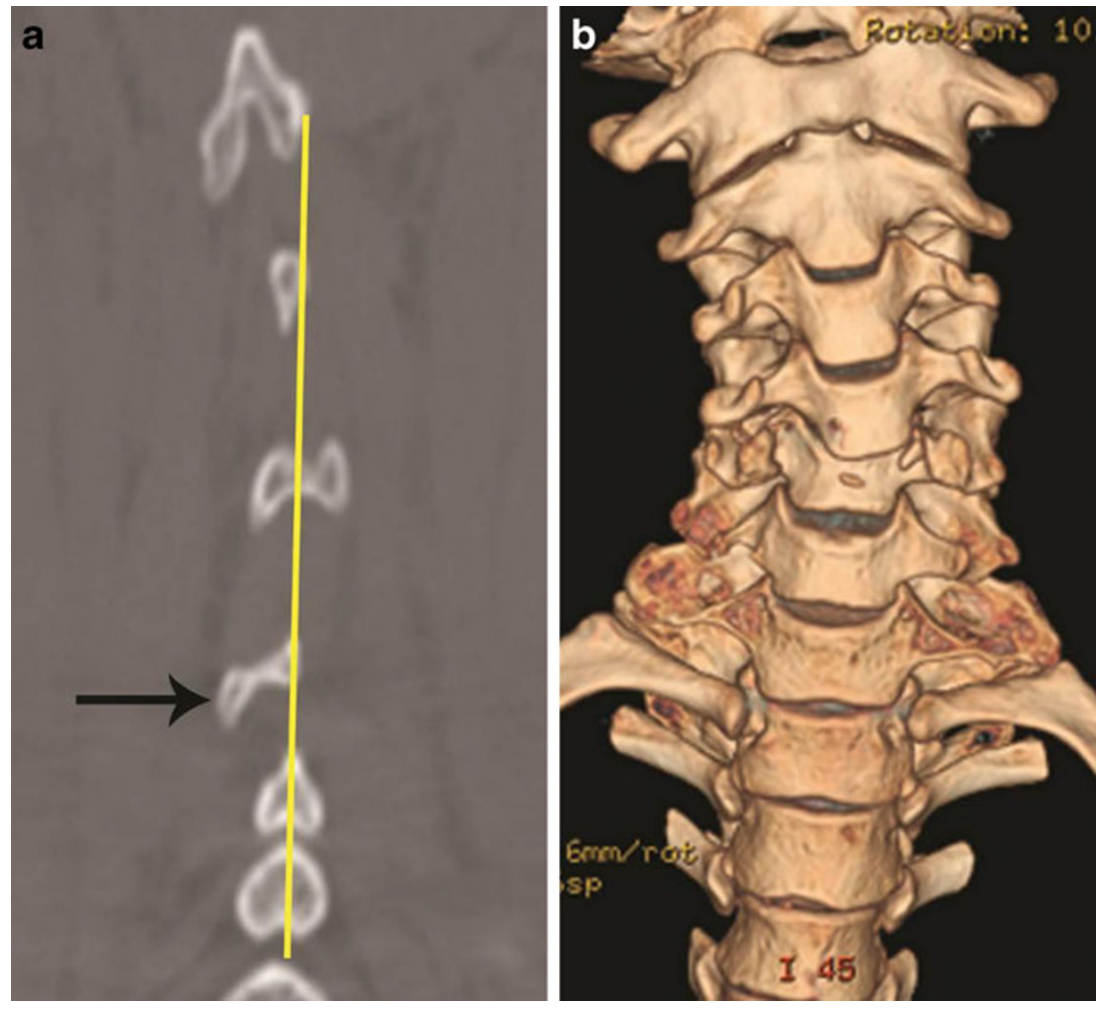

in patients who sustain cervical spine trauma is between 17 and $46 \%$. Most of them are asymptomatic [37-39]. Blunt vertebral artery injury is associated with complex cervical spine fractures involving subluxation, extension into the foramen transversarium or upper $\mathrm{C} 1-\mathrm{C} 3$ fractures [37-40]. CT angiography should be performed in patients with suspected vertebral artery injury.

Table 3 CT features predicting ligamentous and intervertebral disc injury

\begin{tabular}{cll}
\hline & Anterior column & Posterior column \\
\hline $\begin{array}{c}\text { Angulation } \\
\text { rotation }\end{array}$ & Focal kyphosis & $\begin{array}{c}\text { Focal displacement of } \\
\text { spinous process on } \\
\text { coronal plane }\end{array}$ \\
$\begin{array}{c}\text { Translation/ } \\
\text { dislocation }\end{array}$ & $\begin{array}{l}\text { Anterolisthesis } \\
\text { Retrolisthesis }\end{array}$ & - \\
Distraction & $\begin{array}{l}\text { Anterior disc space widening } \\
\text { Posterior disc space widening }\end{array}$ & $\begin{array}{l}\text { Interspinous widening } \\
\text { Interlaminar widening }\end{array}$ \\
& $\begin{array}{l}\text { Intervertebral disc injury: } \\
\text { - Focal disc space widening }\end{array}$ & $\begin{array}{l}\text { Facet joint distraction } \\
\text { spectrum }\end{array}$ \\
& $\begin{array}{l}\text { Avulsion at the anterior or } \\
\text { posterior corner of vertebral } \\
\text { body }\end{array}$ & \\
& - Disc vacuum phenomenon \\
& and diffuse loss of disc & \\
& space height \\
\hline
\end{tabular}

Table 4 CT features differentiating flexion teardrop from burst fractures

\begin{tabular}{|c|c|}
\hline Flexion teardrop (Fig. 8) & Burst fracture (Fig. 10) \\
\hline $\begin{array}{l}\text { Biomechanics - severe } \\
\text { compressive flexion }\end{array}$ & Axial loading \\
\hline $\begin{array}{l}\text { Predominantly anterior VB } \\
\text { compression-resulting in } \\
\text { wedging }\end{array}$ & $\begin{array}{l}\text { VB compression predominantly in } \\
\text { the centre-resulting in diffuse } \\
\text { loss of height }\end{array}$ \\
\hline $\begin{array}{l}\text { Oblique coronal fracture through } \\
\text { the anteroinferior vertebral body. } \\
\text { Fracture does not extend to the } \\
\text { posterior cortex and posterior } \\
\text { cortical line is intact (sagittal CT) }\end{array}$ & $\begin{array}{l}\text { Fracture involves both anterior/ } \\
\text { posterior cortex with disruption } \\
\text { of posterior cortical line (sagittal) }\end{array}$ \\
\hline $\begin{array}{l}\text { Comminution less severe - two/ } \\
\text { three fragments without } \\
\text { centrifugal displacement (axial) }\end{array}$ & $\begin{array}{l}\text { Comminution-severe with } \\
\text { multiple fragments and } \\
\text { centrifugal displacement }\end{array}$ \\
\hline $\begin{array}{l}\text { Retropulsion of the involved } \\
\text { vertebral body along the rest of } \\
\text { the suprajacent cervical spine }\end{array}$ & $\begin{array}{l}\text { Retropulsion commonly from the } \\
\text { postero-superior cortex (sagittal/ } \\
\text { axial) }\end{array}$ \\
\hline $\begin{array}{l}\text { Anterior fragment maintains } \\
\text { alignment with the subjacent VB } \\
\text { (sagittal/axial) }\end{array}$ & $\begin{array}{l}\text { Rest of the spine above and below } \\
\text { maintains alignment }\end{array}$ \\
\hline Focal kyphosis & Normal curvature \\
\hline $\begin{array}{l}\text { Posterior column often distraction } \\
\text { present-interspinous widening } \\
\text { and facet distraction }\end{array}$ & $\begin{array}{l}\text { Posterior column compression } \\
\text { injury or normal }\end{array}$ \\
\hline $\begin{array}{l}\text { Mechanically unstable needs } \\
\text { surgical stabilisation }\end{array}$ & $\begin{array}{l}\text { Mechanically stable. Surgical } \\
\text { treatment indicated for neural } \\
\text { compromise from retropulsed } \\
\text { bony fragments }\end{array}$ \\
\hline
\end{tabular}


Table 5 CT Features differentiating flexion and extension teardrop injuries

\begin{tabular}{ll}
\hline Flexion teardrop & Extension teardrop \\
\hline $\begin{array}{l}\text { Large fragment } \\
\begin{array}{l}\text { Extends to both superior/inferior } \\
\text { end plate }\end{array}\end{array}$ & $\begin{array}{l}\text { Small triangular } \\
\text { Involves only one end plate- } \\
\text { anteroinferior or less } \\
\text { commonly anterosuperior }\end{array}$ \\
$\begin{array}{l}\text { Wedging/compression of VB } \\
\text { Retropulsion of fractured vertebral } \\
\text { body }\end{array}$ & $\begin{array}{c}\text { NB height is preserved } \\
\text { vertebral line is intact }\end{array}$ \\
$\begin{array}{l}\text { Focal kyphosis with flexion } \\
\text { deformity }\end{array}$ & $\begin{array}{c}\text { Normal curvature } \\
\text { Posterior column distraction present- } \\
\text { interspinous widening and facet } \\
\text { distraction }\end{array}$ \\
\hline
\end{tabular}

\section{Biomechanics and management}

Three critical surgical questions can be answered by biomechanics and injury vector based CT analysis:

1. Is there a mechanical instability that needs surgical stabilisation?

2. Which columns need stabilisation - anterior, posterior or circumferential?

3. Is there a need for short or long segment instrumentation?

An "unstable" cervical injury is commonly treated with operative stabilisation, while a "stable" injury may be managed conservatively by immobilisation by traction, collar or observation in bed. Fracture/ligamentous injury involving both load bearing (anterior) and tension (posterior) column suggest mechanical instability. Biomechanical vectors and injury morphology suggestive of distractionrotation and shear-translation result in gross mechanical instability, which needs surgical stabilisation. Flexion teardrop injuries, bilateral facet dislocation and hyperextension distraction injury are also classified as mechanically unstable injuries and need surgical stabilisation. Isolated PLC injury in hyperflexion-distraction injury can results in delayed mechanical instability and should be stabilised and fused.

Anterior, posterior or circumferential stabilisation decision is based on the two essential principles in spine surgery, namely the "tension band principle" and the "load-sharing principle". The column under tensile failure needs stabilisation first to reduce and align the displaced vertebral column; the vertebral body, if injured, can be reconstructed thereafter to share the load of body weight. Anterior longitudinal ligament disruption with disc injury, as occurs in hyperextension distraction injury, mandates anterior surgery with stabilisation and PLC injury as occurs in hyperflexion distraction, generally needs posterior reconstruction and stabilisation. Rotation-translation injuries may disrupt both anterior and posterior stabilising ligaments often requiring circumferential stabilisation.

The length of instrumentation is also often based on the force vectors involved. Significant translation and rotation

Table 6 CT fingerprints and injury vectors

\begin{tabular}{|c|c|c|}
\hline Biomechanics & Anterior fingerprints & Posterior fingerprints \\
\hline \multirow[t]{2}{*}{ Hyperflexion } & Anterior column compression & Posterior column distraction \\
\hline & $\begin{array}{l}\text { Curvature: focal kyphosis } \\
\text { Alignment: anterolisthesis } \\
\text { VB: wedge compression and flexion teardrop. Burst/ } \\
\text { coronal split: axial loading } \\
\text { Disc space: focal posterior widening or diffuse narrowing. }\end{array}$ & $\begin{array}{l}\text { Facet joint: diffuse widening more than } 2 \mathrm{~mm} \text {, focal posterior widening, } \\
\text { subluxation and dislocation } \\
\text { Interspinous widening }\end{array}$ \\
\hline \multirow[t]{2}{*}{ Hyperextension } & Anterior column distraction & Posterior column compression \\
\hline & $\begin{array}{l}\text { Curvature: hyperlordosis or normal } \\
\text { Alignment: normal or retrolisthesis } \\
\text { VB: extension teardrop } \\
\text { Disc space: focal anterior widening/normal }\end{array}$ & $\begin{array}{l}\text { Articular pillar/process fracture } \\
\text { Lamina/spinous process fracture } \\
\text { Pediculo-laminar separation }\end{array}$ \\
\hline Lateral flexion & $\begin{array}{l}\text { Always coupled with rotation. } \\
\text { Frequently associated with hyperextension and } \\
\text { hyperflexion. } \\
\text { Reciprocal compressive and distractive injury on right/left } \\
\text { side } \\
\text { Curvature: coronal plane tilt } \\
\text { VB: lateral compression injury on the side of flexion } \\
\text { Asymmetrical loss of disc height in coronal plane }\end{array}$ & $\begin{array}{l}\text { Reciprocal compressive and distractive injury on right/left side } \\
\text { Unilateral articular pillar or laminar fracture. } \\
\text { Facet joint distraction on the side opposite of posterior element fracture }\end{array}$ \\
\hline Rotation & Usually associated with flexion, extension & $\begin{array}{l}\text { Unilateral facet dislocation or fracture } \\
\text { Asymmetric posterior column injury }\end{array}$ \\
\hline
\end{tabular}

$V B$ vertebral body 
vectors both require long segment stabilisation (two motion segments above and below injury).

\section{Summary}

Cervical spine trauma CT can be interpreted utilising mechanistic principles as described in this article. This approach is based on the principle of identifying the "fingerprints" of the injury on MDCT, suggesting a particular injury mechanism, which leads to a systematic search for the entire spectrum of injuries based on the known pattern of injury produced by the particular biomechanics (Table 6). Both mechanistic and morphology based CT interpretation are complementary and the combination of mechanistic and morphology-based checklist - will help the radiologist to formulate surgically relevant and radiologically accurate report.

Acknowledgements The authors thank Dr. Aymen Al Hadidi, MD, for his assistance and artistic contribution in preparing and processing schematics and images for the manuscript.

No grants were awarded for this project.

Open Access This article is distributed under the terms of the Creative Commons Attribution License which permits any use, distribution, and reproduction in any medium, provided the original author(s) and the source are credited.

\section{References}

1. National Spinal Cord Injury Association Resource Center (2013) www.sci-info-pages.com/factsheets.html. Accessed 12 April 2013

2. Greenbaum J, Walters N, Levy PD (2009) An evidenced-based approach to radiographic assessment of cervical spine injuries in the emergency department. J Emerg Med 36:64-71

3. Goldberg W, Mueller C, Panacek E et al (2001) Distribution and patterns of blunt traumatic cervical spine injury. Ann Emerg Med 38: $17-21$

4. Ryken TC, Hadley MN, Walters BC, Aarabi B, Dhall SS, Gelb DE, Hurlbert RJ, Rozzelle CJ, Theodore N (2013) Radiographic assessment. Neurosurgery 72(Suppl 2):54-72

5. Blackmore CC, Ramsey SD, Mann FA, Deyo RA (1999) Cervical spine screening with $\mathrm{CT}$ in trauma patients: a cost-effectiveness analysis. Radiology 212:117-125

6. Looby S, Flanders A (2011) Spine trauma. Radiol Clin N Am 49: 129-163

7. Grogan EL, Morris JA, Dittus RS et al (2005) Cervical spine evaluation in urban trauma centers: lowering institutional costs and complications through helical CT scan. J Am Coll Surg 200:160-165

8. Daffner RH, Daffner SD (2002) Vertebral injuries: detection and implications. Eur J Radiol 42:100-116

9. Daffner RH, Daffner SD (2006) Vertebral injuries: detection and implications. In: Cassar-Pullicino VN, Imhoff H (eds) Spinal trauma: an imaging approach. Thieme, Stuttgart, pp 81-99

10. Daffner RH, Deeb ZL, Rothfus WE (1986) "Fingerprints" of vertebral trauma: a unifying concept based on mechanisms. Skelet Radiol $15: 518-525$
11. Daffner RH (2011) Anatomical consideration. In: Daffner RH (ed) Imaging in vertebral trauma, 3rd edn. Cambridge University Press, Cambridge, pp 12-13

12. White AA, Panjabi MM (1990) Physical properties and functional biomechanics of the spine. In: White AA (ed) Clinical biomechanics of the spine, 3rd edn. Lippincott Williams \& Wilkins, Philadelphia

13. Schmorl CG, Junghanns H (1968) Die gesunde und kranke wirbesaule in Rontgenbild und klinik, 5th edn. Thieme, Stuttgart

14. Holdsworth F (1970) Fractures, dislocations, and fracturedislocations of the spine. J Bone Joint Surg Am 52:1534-1551

15. Panjabi MM, White AA, Johnson RM (1975) Cervical spine mechanics as a function of transection of components. J Biomech 8: 327-336

16. White AA, Johnson RM, Panjabi MM, Southwick WO (1975) Biomechanical analysis of clinical stability in the cervical spine. Clin Orthop 109:85-96

17. Pitzen T, Lane C, Goertzen D, Dvorak M, Fisher C, Barbier D, Steudel WI, Oxland T (2003) Anterior cervical plate fixation: biomechanical effectiveness as a function of posterior element injury. $\mathrm{J}$ Neurosurg 99(1 Suppl):84-90

18. White AA, Panjabi MM (1987) Update on the evaluation of instability of the lower cervical spine. Instr Course Lect 36:513-520

19. Allen BL, Fergusson RL, Lehmann TR et al (1982) A mechanistic classification of closed indirect fractures and dislocations of the lower cervical spine. Spine 7:1-27

20. Daffner SD, Daffner RH (2002) Computed tomography diagnosis of facet dislocations: the "hamburger bun" and "reverse hamburger bun" signs. J Emerg Med 23:387-394

21. Palmieri F, Cassar-Pullicino VN, Dell'Atti C, Lalam RK, Tins BJ, Tyrrell PN, McCall IW (2006) Uncovertebral joint injury in cervical facet dislocation: the headphones sign. Eur Radiol $16: 1312-1315$

22. Bono CM, Schoenfeld A, Rampersaud R, Levi A, Grauer J, Arnold P, Fehlings M, Dvorak M, Vaccaro AR (2011) Reproducibility of radiographic measurements for subaxial cervical spine trauma. Spine 36:1374-1379

23. Daffner RH, Harris JH (2013) Cervical spine injuries. In: Harris JH (ed) The radiology of emergency medicine, 5th edn. Lippincott Williams \& Wilkins, Philadelphia, pp 139-260

24. Favero KJ, Van Petegham PK (1989) The quadrangular fragment fracture: roentgenographic features and treatment protocol. Clin Orthop 239:40-46

25. Vives MJ, Vaccaro AR, Abitbol JJ (2003) Compressive flexion injuries of the cervical spine. In: Vaccaro AR (ed) Fractures of cervical, thoracic and lumbar spine, 1st edn. Marcel Dekker, New York, pp 207-218

26. Vaccaro AR, Hulbert RJ, Patel AA, Fisher C, Dvorak M, Lehman RA, Jr. et al (2007) The subaxial cervical spine injury classification system: a novel approach to recognize the importance of morphology, neurology, and integrity of the disco-ligamentous complex. Spine 32(21):2365-2374

27. Vaccaro AR, Madigan L, Schweitzer ME, Flanders AE, Hilibrand AS, Albert TJ (2001) Magnetic resonance imaging analysis of soft tissue disruption after flexion-distraction injuries of the subaxial cervical spine. Spine 26:1866-1872

28. Carrino JA, Manton GL, Morrison WB, Vaccaro AR, Schweitzer ME, Flanders AE (2006) Posterior longitudinal ligament status in cervical spine bilateral facet dislocations. Skelet Radiol 35:510-514

29. Crawford NR, Duggal N, Chamberlain RH, Park SC, Sonntag VK, Dickman CA (2002) Unilateral cervical facet dislocation: injury mechanism and biomechanical consequences. Spine 27:1858-1864

30. Beatson TR (1963) Fractures and dislocation of the cervical spine. J Bone Joint Surg Br 45B:21

31. Lingawi SS (2001) The naked facet sign. Radiology 219:366-367 
32. Shanmuganathan K, Mirvis SE, Levine AM (1994) Rotational injury of cervical facets: CT analysis of fracture patterns with implications for management and neurologic outcome. AJR Am J Roentgenol 163:1165-1169

33. Rao SK, Wasyliw C, Nunez DB Jr (2005) Spectrum of imaging findings in hyperextension injuries of the neck. Radiographics 25: 1239-1254

34. Shanmuganathan K, Mirvis SE, Dowe M, Levine AM (1996) Traumatic isolation of the articular pillar: imaging observations in 21 patients. AJR Am J Roentgenol 166:897-902

35. Taljanovic MS, Hunter TB, Wisneski RJ, Seeger JF, Friend CJ, Schwartz SA, Rogers LF (2009) Imaging characteristics of diffuse idiopathic skeletal hyperostosis with an emphasis on acute spinal fractures: review. AJR Am J Roentgenol 193(3 Suppl):S10-S19
36. Hogan GJ, Mirvis SE, Shanmuganathan K et al (2005) Exclusion of unstable cervical spine injury in obtunded patients with blunt trauma: is MR imaging needed when multi-detector row CT findings are normal? Radiology 237:106-113

37. Cothren CC, Moore EE, Biffl WL et al (2003) Cervical spine fracture patterns predictive of blunt vertebral artery injury. J Trauma 55:811813

38. Biffl WL, Moore EE, Offner PJ et al (2001) Blunt carotid and vertebral arterial injuries. World J Surg 25:1036-1043

39. Biffl WL, Moore EE, Elliott JP et al (2000) The devastating potential of blunt vertebral arterial injuries. Ann Surg 231:672-681

40. Malhotra AK, Camacho M, Ivatury RR et al (2007) Computed tomographic angiography for the diagnosis of blunt carotid/ vertebral artery injury: a note of caution. Ann Surg 246:632 